$$
\text { AGARDH, J.G. }
$$





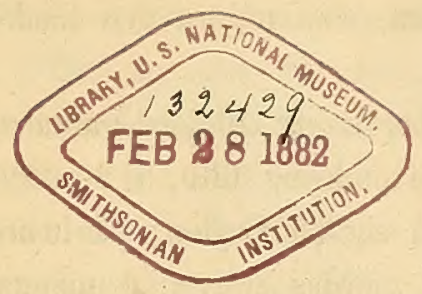

\title{
Bidrag till Florideernes Systematik.
}

\author{
J. G. AGARDH.
}

(Vid Physiographiska Sällskapets möte d. 21 Dec. 1870 delvis meddelade).

$\mathrm{U}_{\mathrm{ti}}$ i ett föregånde arbete, Species Genera et Ordines Algarum, Lunda 18481863, har ett försök blifvit gjordt att ordna Florideerna i naturliga grupper. Oaktadt det material, jag dertill haft att disponera öfver, sannolikt varit det rikaste och fullständigaste, som någonstädes torde förefunnits, lemnade detta, af lätt begripliga skäl, dock mycket öfrigt att önska. Af många Alger äger man ännu i denna dag endast exemplar utan frukt; af andra finnas ofta exemplar med endast det ena af de båda slags fruktorganer, som förekomma hos Florideerne på olika individer; snart sagdt af ingen Floridée ägde man då i föregående arbeten så beskaffade analyser af fructificationsdelarne att de kunde begagnas, då systemet skulle grundas på dessa delars inre structur. Då ett första systematiskt försök framkommit under sådane fårhållanden, torde det icke vara att undra öfver om detta i många afseenden blifvit ofullständigt, eller kommit att innehålla en och annan oriktigh? et.

Sedan dess har både bättre material i afseende på de förut kända arterne vunnits, som ock en stor mängd nya Alger blifvit från de mest aflägsne trakter hemförda, hvilka fyllt mången lucka $\mathrm{i}$ systemet och som här och hvar torde föranleda en annan gruppering äfven af de förut kända Algerne. Det är ett försök i sådan riktning, i afseende på några af Florideernes grupper, som härmed framlägges.

Under ingen period af Algologiens historia torde ett större antal nya och egendomliga former uppdagats än just under de år som närmast följde utgifvandet af de 2:ne första delarne af Species Algarum, hvilka afhandla Florideerne. Ensamt Prof. Harveys expedition till nya Holland, utförd under åren 1853-56, medförde icke blott det största material, som någonsin kommit Algologien till del, után gaf Lunds Univ. Årsskrift. Tom. VIII. 
jemväl upphof till flera arbeten, som utgöra den moderna vetenskapens största prydnader.

Enligt Harveys egen beräkning utgjorde antalet af de af honom ensamt från nya Holland hemförde arterne omkring 600, i 20,000 exemplar. Pa ditresan hade han haft tillfälle att uppehålla sigg på Ceylon; på hemvägen vid flera af Stilla Oceanens olika kuster; öfverallt gjordes större insamlingar. De Harveyska exemplaren hafva sedan blifvit Algologerne bekanta genom distribuerade samlingar.

Att Harvey vid arternes bestämning oeh ordmandet af det ofantliga material, som han medfört, begått ett och annat fel, torde icke förundra någon, som känner huru lika många Alger sins emellan äro, och huru lätt sålunda misstag kunna begås. Flera sådane fel corrigerade han sjelf uti sednare arbeten. En noggrannare analys än som under en resa kan medhinnas och nogare jemförelse med andra arter torde visa att ännu en och annan art lämpligare kunnat hänföras till andra slägten. I afseende på någras slägtskap har jag sålunda fått en annan uppfattning än Harvey, hvarföre i det följande närmare skall redogöras.

\section{Cryptonemea.}

Sådan denna grupp uppfattades i Species Algarum torde den ännu kunna bibehållas, ehuru cystocarp-fruktens bildning hos afdelningen Gasterocarpeæ i någon mån torde vara afvikande från de andras och möjligen framdeles fordra Gasterocarpeernes särskiljande. Bättre material och noggrannare jemförelse hafva emedlertid lärt, att några af de slägten, som hänfôrdes till Cryptonemeæ, derifrån böra uteslutas. I en sednare del af det nämnda arbetet har jag redan antydt att Fauchea och Epymenia borde hänföras till Rhodymenieæ; likaså torde Chrysymenia böra öfverflyttas till denna grupp. Furcellaria, som genom sin fruktbildning så mycket afviker från de andra Florideerne, torde måhända närmast vara beslägtad med Cystoclonium. Obekant med cystocarp-frukten hos den typiska arten af slägtet Acrotylus, hänförde jag detta slägte till Cryptonemex, under antagande att cystocarpfrukten skulle hos den typiska arten vara öfverensstämmande med den hos en annan art, som jag antog tillhöra samma slägte. Det har dock sedan visat sig att Acrotylus australis har cystocarp-frukten mycket olika bildad, så att icke blott de nämnde arterne måste skiljas i olika slägten, utan dessa äfven hänföras till olika grupper. 
Deremot torde slägtet Polyopes böra ifrån Gigartineæ öfverflyttas till närheten af Grateloupia och Prionitis. Desmia, som på grund af structuren af frons hänfördes till Sphærococcoideæ, har visat sig äga en fruktbildning, som kanske närmast öfverensstämmer med Rhizophyllis. Ett nytt slägte, Ochtodes, som här nedan uppställes, kommer Desmia mycket nära; och måhända torde det ännu mycket ofullständigt kända slägtet Gloiocladia böra uppställas i de sistnämnde slägtenas närmaste granskap. Att det så egendomligt bildade slägtet Thamnoclonium bör hänföras till Cryptonemeæ, har jag i en sednare del af Species Algarum redan sökt ådagalägga.

Såsom bidrag till kännedomen af särskilda arter och slägten skall jag ännu tillägga följande:

Gratelonpia undulata (I. Ag. mscr.) frondibus simpliciusculis aut parce divisis, a foliolo senili reducto palmatim aut pinnatim egredientibus, carnoso-membranaceis planis lanceolato-linearibus utrinque attenuatis, margine sæpissime eximie undulato, demum crenulato ligulisque sparsim obsito, cystocarpiis per totam frondem densis, sphærosporis sparsis.

Ad Insulas Indiæ Occidentalis.

Inter Gr. cuneifoliam et Gr. Cutleriæ intermedia, nec cum Gr. Gibbesiï Harv. bene conjungenda. Nune ultra pedalis, latitudine segmentorum $2-3$ pollicari, nune minor et irnmo adspectum præbens Porphyræ cujusdam; nostra specimina semper chartæ adhærentia.

Corynomorpha I. Ag. mscr. Acrotyli sub-genus Prismatoma I. Ag. sp. p. 193.

Frons in una specie, a Harvey descripta, teretiuscula et clavata, in altera (ex mente Harveyi) recens teretiuscula, exsiccata 3 -4-quetra, mihi adparuit acido suffusa eandem formam prismaticam conservans, subtubulosa, tubo interiore filorum adparatu laxiori percurso. Fila media magis longitudinalia, exteriora magis verticalia et anastomosibus paulo densioribus juncta; hæc demum fila moniliformia strati corticalis emittentia. Fila interiora - canali articnlato eolorato percursa. Apex frondis fere spongiose inflatus teretiusculus, filis corticalibus hoc loco multiplo longioribus et strictioribus, dense adproximatis constans. Iu cryptis infra peripheriam excavatis et circum-ambientibus filis tenuioribus, quasi ad orificium (carpostomium) inter fila nemathecii secedentia formatum ducentibus, tecti nuclei simplices, at plurimi adproximati, nidulantur. Gemmidia in nudeo plurima et sine ordine conspicuo conglobata, facile diffluentia.

Genus nuclei structura ducente ad Cryptonemeas pertinens, evolutione cystocarpiorum inter fila nematheciosa Rhizophylleis analogum, aliis ut videtur characteribus 
abludens; nuclei structura et gemmidiis facile diffluentibus forsan Polyopi proximum.

Species mihi sunt:

1. C. prismatica $I$. Ag. $l$. $c$.

2. C. clavata Harv. Ner. Bor. Am. p. 196.

Desmia I. Ag. sp. p. 639.

Cystocarpia sat bene evoluta in pluribus speciebus vidi. A superficie frondis verrucæ, pro magnitudine plantæ sat magnæ, angustiori basi affixæ, hemispherice effusæ proveniunt, filis radiantibus, moniliformiter articulatis, dichotomo-fastigiatis constantes. Inter hæc fila nuclei adparent plurimi, initio vesicam coloratam, qualem in aliis generibus quandoquidem quoque vidi, contento fluido ut videtur impletam, constituentes; serius endochroma in partes collapsum videre credidi; maturi nuclei constant gemmidiis plurimis minutis conglobatis, muco et ambientibus filis paucis quandoquidem cohibitis; nuclei ejusmodi plurimi intra verrucas singulas inclusi, sensim densiores magisque adproximati, demum quasi in nucleum compositum coalescentes. Filorum nemathecii articuli ultimi firmius cohærentes, quasi membranam externam verrucæ nematheciosæ præbent.

Kützing, in ultimo suo opere (Tab. Phyc. vol. 17 tab. 95), structuram, quam fructibus tribui, fere eandem pinxit, nucleos vero antheridia esse suspicatus est; forsan nimium juveniles vidit; in nostris nuclei ab aliis Cryptonemearum non admodum recedunt.

Conformatione totius fructus Desmia cum Ochtode fere convenit, nec a Rhizophyllide, si quidem a descriptione Montagnei de hac re judicare licet, admodum alienum videtur. Nucleis singulis simplicibus, at plurimis intra verrueam nemathecioideam collectis, sensim dense adproximatis et demum fere confluentibus, totum hunc adparatum quasi nucleum compositum forsitan quis consideraret.

Species plures quam fas fuit in hoc genere distinctas fuisse, credere licet; interea enumero sequentes hodie cognitas:

1. D. pulvinata (D. ambigua var. pulvinata Harv. Alg. ceyl. n:o 91).

2. D. tripinnata Hering.

3. D. coccinea; Porlieria coccinea Zanard. in Regensb. Fl. $1851 \mathrm{p.} 3 \% \mathrm{Pl}$. Mar. Rubr. p. 55. Plocamium circinnatum Mont.; Kütz tab. Phyc. Vol. 16 tab. 47 .

\section{D. ambigua Grev.}

5. D. Hornemanni Mert. 
Ochtodes ( $I$. Ag. mscr.) Frons cylindracea dichotoma aut vage ramosa, maximopere gelatinosa (iterum madefacta facillime dissoluta), subcartilaginea; juvenilis subtubulosa, filis moniliformibus ab axili siphone provenientibus constituta; adultior intus cellulosa farcta, tribus stratis constituta: axili siphone cincto minoribus arcuatim inter cellulas strati medii rotundatas laxe cohærentes excurrentibus; corticalibus filis moniliformibus brevioribus. Cystocarpia in verrucis nemathecioideis rotundatis a fronde erumpentibus dense aggregatis evoluta, nucleis pluribus inter fila radiantia nemathecii suspensis constituta; nuclei gemmidia minuta plurima, sine adparenti ordine conglobata, muco cohibita foventes. Sphærosporæ - - -

Fronde juvenili dissecta siphonem articulatum axilem vidi, filis corticalibus moniliformibus fastigiatis laxe circumdatum. Frons hoc modo quasi tubulosa sensim solidescit, articulis filorum interioribus in cellulas magis rotundatas intumescentibus, aliis filis sparsissimis inter cellulas vacua implentes excurrentibus, (structura fere Callophyllidis). Strati corticalis fila moniliformia in adultiore fronde minus conspicua, articulis cellulas seriatas magis xmulantibus. Adulta frons hoc modo cellulosa adparet et farcta, sed facillime dissoluta. Fructus ejusdem omnino naturæ vidi ac eos, quos in Desmia jam descripsi; verrucæ autem minores, dense aggregatæ, plures demum, ut videtur, confluentes.

Fructu ignoto species duas ad calcem Sphærococci Generis in Spec. Algarum enumeravi, supposita unius cum Chondrococco filiformi Kütz identitate. Postea suam speciem icone data, in Tab. Phyc. vol. 17 tab. 95, illustravit Kützing, addita analysi structuræ, quæ non bene in nostram speciem cadit. - Species mihi sunt:

1. Dcht. filiformis I. Ag. sp. p. 644. Acanthococcus adelphinus Mont. in Ann. Sc. Nat. fide specim. a Crouan missi.

variat: cervicornis ramulis magis patentibus, terminalibus subdivaricatis rigidiusculis. Fructus supra descriptos in hac vidi.

Hab. in mari Antillarum.

2. Ocht. capensis I. Ag. l. c. p. 645 .

Ad Cap. B. Spei.

Cryptonemia. Species sec. habitum duos quasi diversos typos referre, et structuram diversa ætate quodammodo diversam esse, meminisse opportet. Fila interiora sunt nimirum laxiora in juvenilibus, densiora et immo densissima in adultioribus partibus. Stratum corticale, fere eodem modo diversum, in partibus juvenilibus constat filis fere moniliformibus at abbreviatis; in adultioribus fila in cellulas magis adproximatas mutantur; in sphærosporifera parte stratum corticale fere nematheciose evolutum est. Infra stratum corticale intermedium stratum quodammodo adest, in par- 
tibus juvenilibus vix conspicuum, infra sores ut fila anastomosantia obvium; in partibus adultioribus cellulæ interiores strati corticalis majores rotundatæ, arete adproximatæ, nune quasi granuloso contentu instructæ sunt, quo fit ut hoc stadio admodum conspicuæ, quasi stratum proprium efficientes, adpareant. Sit ut in diversis speciebus hæ diversitates plus minusve conspiciantur; vix vero is ducentibus species alio respectu simillimas in diversa genera distrahere decet. Quæ omnia dicere debui, ut intelligatur quo jure species quasdam, ad alia genera relatas, ad Cryptonemiam revocandas esse urgeo. Species nimirum milhi sunt sequenti modo disponendæ:

I. Acrodiscus fronde segmentis regularibus dichotoma aut subpinnatifida, prolificationibus conformibus a margine nunc instructa; segmentis terminalibus aut phyllis prolificantibus soro nemathecioso intramarginali elongato, aut scepius infra apicem brevi, rotundato instructis.

* Fronde fere omnino ecostata.

1. Cr. dichotoma I. Ag. sp. p. 225.

2. Or. ligulata; Gymnogongrus ligulatus Harv. Alg. exs. Ceyl. n:o 50.

Nee structura frondis, nec sphærosporæ sunt Gymnogongri! Habitus mire Prionitidem refert, et facile quis crederet Sphær. chondrophyllum Boryi, quem ad Prionitidem retuli, cum Cr. ligulata identicum esse. Fragmentum plantæ Boryanæ, quod comparavi, habet segmenta paulo angustiora quam specimina Harveyana. Structuram plantæ Boryanæ bene recognoseere mihi non licuit; cum specie Prionitidis e Mari Coreano Boryanam plantam identicam assumsi. - Sori sphærosporarum in planta Harveyana adsunt, in segmentis terminalibus phyllisque marginalibus, elongati intramarginales!

3. Cr. denticulata I. Ag. sp. p. $33 \%$.

4. Cr. crenulata $I$. Ag. ibm p. 225.

* Frondibus inferne sensim costatis, costa incrassata externe evidentius conspicua, phylla prolificantia demum sape generatura.

5. Cr. rigida Harv. Alg. Ceyl. exsicc. n:o 51.

6. Or. phyllophora; Acropeltis phyllophora Harv. Phyc. austr. tab. 283.

Nomine Cryptonemia? decipientis Harvey (in Phycol. austr. tab. 289) speciem quandam a sua Acr. Phyllophora distinxit; has duas externa facie simillimas, structura vero in eo diversas dixit, quod cellulæ intermediæ in Acr. phyllophora ratundatoangularæ contiguæ sunt, in Cr. decipiente vero minores, invicem distantes et anastomosibus junctæ pinguntur. Ejusmodi differentia vero etiam in aliis speciebus adest. Partes juveniles et soriferi monstrant structuram, quam Cr. decipienti tribuit; utrum vero differentiæ sint ætatis, an a diverso statu speciminum pendeant in speciebus 
allatis Harveyanis contendere non audeo, quum specimina authentica in his comparare mihi non licuit.

7. Cr. elata Acropeltis elata Harv. Phyc. austr. tab. 122.

II. Cryptonemia. I. Ag. sp. l. c.

8. Cr. seminervis. Ag.

var. phyllantoides caule elongato ramoso, foliolis singulis cuneato-oblongis semicostatis, a margine phylla capsulifera minuta linearia aut oblonga utrinque dense seriata emittentibus

var. palmata caule alato in laminam palmato-decompositam demum evanescentimulti-costatam, foliolisque conformibus a margine pullulantibus instructam abeunte. Phylloph. nervosa Welw. Phyc. Lusit n:o 195.

9. Cr. Lactuea $A g$.

10. Cr. Lomation Bert.

11. Cr. Inxurians Mert.

12. Or. undulata Sond.; Harv. Phyc. austr. tab. 205.

Thamnoclonium. Fructus uterque in phyllis minutis propriis, superficie everrucosa distinguendis, evoluti: cystocarpia immersa in cryptis numerosis infra stratum corticale, fere in fila verticalia evolutum, excavatis, secedentibus filis apertis, nucleos singulos simpliciusculos foventia; nucleus gemmidia minuta plurima angulato-rotundata, vix distincto ordine conglobata, quasi muco cohibita fovens. Sphærosporæ in phyllis aggregatæ cruciatim divisæ.

Genus cum Polyope fere convenit proventu fructuum in phyllis prolificantibus proprïs, eystocarpiis immersis, sphærosporis cruciatim divisis inter fila corticalia subnematheciose evolutis; nec nuclei structura admodum diversa. Gemmidia in lobulis pluribus quasi formata, laxius conjuncta quam in plurimis Cryptonemeis, quasi muco cohibita. Plexus concentricus nucleum ambit, filis carpostomium versus convergentibus. Pbylla minuta cystocarpiis onusta sunt filis interioribus laxioribus quam in sterili fronde contexta. A plurimis distat genus habitu, phyllis fructiferis evidentius a sterili frondis distinctis. Structura anatomica a Polyope longe recedit.

Genus sectiones duas hodie comprehendit, olim distinguendas: primam genuinam; alteram crescendi modo, ab ipsa dispositione filorum interiorum pendente, sat alienam. In hac sphærosporæ, in nematheciis provenientes, distinctionem quoque urgent.

* Thamnoclonium frondium ramis contiguis, verrucis circumcirca obtectis. 
1. Th. diehotomum I. Ag. in Linn. 1841 p. 3. Th. hirsutum Kütz; Harv. Phyc. austr. tab. 293.

var. Codioides fronde duplo crassiore, setis hyalinis numerosioribus.

2. Th. Lemamianum Harv. Phyc. austr. tab. 114.

** Dictyophora frondis caulescentis ramis in expansiones foliaceas, reticulo ramellorum filiformium compositas abeuntibus, laciniis periphericis reticuli liberis, hic illic membranaceo-dilatatis, sursum increscentibus, deorsum sensim in reticulum distractis.

3. Th. Rabelliforme Sond; Harv. Phyc. austr. tab. 113.

\section{Gigartineæ.}

I Species Algarum upptogs under den allmänna benämningen Gigartineæ 5 mindre grupper, deraf de 2:ne Endocladiece och Rissoellece numera lämpligare torde kunna finna plats på andra ställen i Systemet. De 3:ne öfriga, hufvudsakligen öfverensstämmande i cystocarpfrulstens byggnad, torde fortfarande kunna betraktas som underafdelningar af Gigartineæ, och med bibehållande af den begränsning de redan erhållit, endast med den skillnad, att slägtet Stenogramme öfverföres till Kallymenieæ; att Furcellaria får plats närmast Cystoclonium; och möjligen slägtet Gloioderma, hvars cystocarp-frukt ännu är okänd, framdeles torde böra till annan plats definitivt förflyttas. Ett nytt, serdeles utmärkt slägte Erythrophyllum, som här nedanför beskrifves, torde möjligen utgöra Kallymenieernes högsta form, analog med Delesseria inom Sphærococcoideernes grupp. Några utmärktare nya arter tillåter jag mig här beskrifva.

Iridara membranacea (I. Ag. mscr.) fronde gelatinoso-membranacea plana lanceolata, supra stipitem planatum simpliciuscula, dichotoma aut a margine folii senilis sæpe reducti pinnatim aut palmatim laciniata, marginibus sæpius crenulatoinæqualibus, soris sphærosporarum majoribus subprominulis, cystocarpiisque per totam frondem superiorem densis.

Ad Valparaiso.

Specimina hujus, ut videtur, sæpius in Herbariis nomine Grateloup. Cutleriæ servantur, et huic revera externe simillima sunt; sed planta minor, vix pedalis, et fructu Iridææ prædita. Nucleus cystocarpii nempe compositus ut in Iridæa, nec simplex ut in Grateloupia. Sphærosporæ quoque in soros collectæ, nec sparsæ ut 
in Grateloupia: Soros pro nucleo Cystocarpii Grateloupix forsan habuerunt, sed sunt ambitu multo majores, ita ut nudo quoque oculo specimina dignoscantur.

Gigartina Jardini ( $I . A g . m s c r$.) fronde canaliculato-plana lineari subpinnatim decomposita, segmentis supra basem angustiorem linearibus elongatis apice truncatis dentatisque, papillis a disco et margine proliticantibus lingulato-lanceolatis subcanaliculatis cystocarpia singula submutica infra apicem gerentibus.

Ad Californiam (Hb. Le Normand!).

Est quasi Gig. mamillosæ forma magis elongata, fere pimnatim composita. (Sub nomine G. lanceolatx in Hb. Le Norm. a me hre indicata fuit; alia vero specie a Harvey sub eodem nomine descripta, nostrum mutare debui).

Kallymenia perforata ( $I$. Ag. mscr.) gelatinoso-membranacea subvage laciniata, laciniis demum sublinearibus serie foraminum grosse cribrosis, foraminibus junioribus rotundatis, adultioribus obiongis multo majoribus, kalidiis minutis inter foramina sparsis.

\section{Ad Ceylonam (in Hb. I. E. Gray).}

Una cum K. cribrosa Harv. hæc species sectionem propriam (aut subgenus) Kallymeniæe coustituere mihi adparuit, quam Zeiræ nomine designavi. Frons in hac sensim foraminibus cribrosa, ut in Agaro aliisque norma sit; strata exteriora frondis admodum tenuia, filisque interioribus sparsioribus distenta; cellulæ corticales fere unica serie disposite.

Formam et divisionis modum omnino fere refert Ulvæ reticulatæ Forsk; sed rosea, madefacta dilutissime carnoso-rosea subpellucida, aquoso-gelatinosa, membrana vero tenaci constituta, exsiccata obscurior. Laciniæ forma lineares, 3 lineas sæpius latæ, in medio sensim serie foraminum pertusa; foraminibus increscentibus atque demum confluentibus, margines ut laciniæ novæ separantur, suo ordine dilatatæ perforatæ et in novas disjunctæ. Foramina a diametro lineæ usque $2-3$ lineas et quod exsuperat attingunt. Charæe arctissime adhæret. Fructus bene evolutos, at paucissimos sparsos vidi.

Kallymenia phyllophora ( $\mathcal{I}$. Ag. mscr.) fronde carnosa lanceolato-lineari subindivisa, a disco aut sæpius intra marginem prolifera, prolificationibus conformibus basi attenuata nune subobliqua sessilibus, kalidiis ab apice deorsum infra medium folii per totam superficiem densis.

Ad Insulam Vancouver (D:r Wood, in Hb. I. E. Gray).

Sectionem propriam Kallymeniæ hæc quoque species sibi vindicare videtur. Obiter inspecta frons fere pinnata adparet: prolificationes nimirum intra marginem emergunt, quæ ordine et fere pinnatim dispositæ videntur. 
Frondem vidi 3 pollicarem planam et carnosam, dimidium pollicem vix latam, prolificationibus subpinnatim dispositis ramosam. Phylla prolificantia unue a medio disco, nunc et sapius paulo intra maroinem exemtia, simplicia, 3-pollicaria, fere lanceolato-linearia, basi abruptius attenuata sessilia, nume fere obliqua et subfalcata, ab apice et longe infra medium fructifera kalidiis deuse sparsis, porn in exsiccata conspicuo pertusis. Color obscure purpureus. Chartæ laxius adhæret.

Structura et fructus generis videtur. Stratum internum constat cellulis cylindraceis anastontosantibus, quasi granulosa materia farctis; hæ utrinque abeunt in cellulas magis rotundatas strati intermedii majores; superficialibus cellulis minutis seriatis. Kalidia strato interno immersa, pluribus nucleolis constituta, singulis fasciculo tenui filorum anastomosantium separatis. Gemmilia in nostra non arcte cohærent.

Ab omnibus mihi coguitis Kallymeniæ speciebus facile distincta, forma sua exsiccatum specimen Splachnidii quodammodo refereus, ramificationis norma Sarcomeniam. Specimen a me visum superiorem partem planta tantun sistit; si stipes distinctus adesset, fere æequo jure ad Constantineam referreretur, ignotis sphærosporis, quas in his generibus diversas esse constat.

Gracilaria fastigiata $I . A g . s p . p .600$ est mihi hodie species Callophyllis. Diu sterilis tantum observata, a Hookero et Harvey nomine Rhodymeniæ soboliferæ in Flora antaretica primum indicata fuit. Cyslocarpia demum vidi iis Callophyllidis omnino similia.

Stenogramma, genus diu cognitum, at difficitius disponendum, ad Callophyllidem aftinitate proxime accedere putarem. A me, fructu nondum perspecto, ad Rhodymenieas relatum; a Harvey, qui fructus in plurimis bene illustravit, eodem systematis loco relictum; Kützingius ad Delesserieas retulit duce C. Agardh, qui speciem typicam Dutesserix speciem consideraverat. Cystocarpiorum forma elongata linearis, quam, si Rhodymenieis relerreretur, agre explicarem, facilius revera intelligatur, ut plurimis nucleolis seriatis nucleus compositus agnoseatur.

Erythrophyllum I. Ag. mser.

Frons foliformis costata, venisque obscuris percursa, fere tribus stratis contexta: filis interioribus articulatis subfasciculatim conjunctis costam formantibus; cellulis rotundato-oblongis laxius dispositis, reticulo filorum anastomosantium cinctis, lamina stratum internum constituentibus; cellulis corticalibus minutis granuliformibus monostromaticis. Fructus ignoti.

Genus novum insigne, forma frondis Delesserieam revocans, structura Kallymeniæ aut Callophyllidi proximum, et, si rite auguror, his formam superiorem costa præditam constituens. His dietis me non fugit Genus Harveyanum Chauviniæ fere 
iisdem characteribus conditum esse ef codem modo a Delesseria differre. Chauvinias vero Delesserieis pertinere, nulis dubiis vacat; substantia contra Erythrophylli et adspectus is est, ut genus nullo modo Delessericis aduumerandum esse assumere audeam.

Frons folium fere lanceolatum, plus quam semipedale longitudine, et bispollicem latum referi, costa superne evanescente, inferue in stipitem lamina detersa subdentatum ancipitem desinens. Margines inxquales velut foramina adultiora, quibus frons hic illic pertusa cernitur, sunt brevissimis spinulis ciliolatx; in his cilis fructus denum evolvi, forsan credere licet. Venæ olsscuræ, parum conspicuæ, ut videtur sine ordine vagx, furcate ot subflexuosa: (nec strictx), juxta costam evidentiores, lateraliter excurrunt, margines versus evanescentes. Inter cilia margines quasi minutissime erosi. Stipes ab expansione radicali surgens, in nostro bipollicaris, anceps, margine angusto in dentes alternas abeunte, dein costa lamina continuatus. Ipsa lamina oblique deorsum a margine, costam versus, hic illic fissa.

Si particula juvenilis frondis (ex. gr. eilia) dissecta observatur, adparet stratum internum contextum filis tenuissinis, aliis longitudinalibus, aliis transverse excurrentibus, dense invicem interjectis, hic illic inflatis in cellulam ramosam et anastomosantem, quæ ita fit in exteriore parte caulis et in lamina tota cellulis rotundatis origo; fila excurrunt in cellulas periphericas, quæ sunt quasi rami extimi filorum. In adultiore parte fila permanent, in costa densiora, peculiare stratum efficientia; in lamina fila cellulas circum-ambientia constituunt; longitudinali sectione celIula oblonga strati intermedii, infra superficiem utramque præcipue conspicuæ, sunt vagæ (nec alterna nec e regione positæ ut in Delesserieis), centralibus cellulis Chauvinia omnino deficientibus. Costa constat strato interiore amplissimo, filis quasi fasciculatim longitudinaliter excurrentibus, articulatis, articulis cylindraceo-clavatis endochroma granulosum continentibus. Cellulæ rotundato-angulata strati intermedii directione tangentis latiores videntur et a facie quasi depressæ; inter has, laxius dispositas, adparatus filorum reticulatim ambientium adest. Stratum corticale cellulis minutis granuliformibus colorato succo impletis, fere simplici serie dispositis, nec în fila verticalia moniliformia conjunctis. His quasi punctata, frons a superficie visa cernitur; ipsa membrana hyalina.

Lrythr. Delesserioides (J. Ag. mscr.) fronde subpedali ambitu lanceolata, sparsim a margine et oblique costam versus lacera, margine demum minute ciliata. Hab. ad insulam Vancouver: D:r C. B. Wood (in Hb. I. E. Gray).

Obs. Ad genus Ahnfeltixe prater species a me in Specieb. Algarum adnissas, nova quædam forsan potissimum reterantur, quas antea nune Gracilariæ, nunc Gymmo- 
gongro retulerunt. Ejusmodi sunt: Gigartina torulosa Hook. et Harv. in Lond. Journ. IV. p. 546, qux postea ut Gracilaria? torulosa in Lond. Journ. VII et I. Ag. Sp. p. 605 et demum ut Gymnog. furcellatus var. in Fl. Nova Zelandice admissa fuit. Hæe ab Ahnfeltia distat fronde magis carnosa, cellulis strati interioris stellatim radiantibus, nempe invicem distantibus et radiis angustioribus junctis. Ita quoque de Plocaria? furcata Hook. et Harv. in Lond. Journ. IV. p. 545, I. Ag. Sp. p. 606. Gymnogongrus furcatus Harv. in Fl. Nov. Zel. judico; hujus est frons subcornea, cellulis strati interioris subdistantibus, nempe interjectis filis reticulatim ambientibus, in axi densioribus. Ignotis sphærosporis xgre dicitur utrum ad ipsum Ahnfeltiæ genus referantur, an potius in ejusdem vicinia disponantur.

Gymm. crenulatus Turn. Hist. tab. 40, quamquam a Turnero in propria dissertatione (Linn. Trans. VI p. 130) illustratus, planta tamen dubia et obscura plurimis sine dubio permansit, recentiori tempore a nemine iterum inventa. Specimen originale, a Turnern datum, in Hb. C. Agardh speciem G. norvegico proxinam indigitare adparuit; characteres distinctionis vero non admodum perspicui mihi, Species Algarum seribenti, obvenerunt. Poster inter Algas a Prof. Lange ad St. Sebastian lectas, specimen plantæ pulchra et distinctissimæ vidi, in qua speciem 'Turnerianam recognoscere credidi. Margines sunt minute, at eximie et evidentissime crenulati, ita ut Caloph. laciniatan ante oculos habere fere crederes. Nec structura admodum abhorreret, at nemathecia adsunt! caterum multo angustior. Specimina Turneriana vix diversa nisi crenulis multo magis obsoletis; forsan aut undis circumjecta aut diverso stadio lecta fuerunt. Sequentibus itaque characteribus speciem distinguendam putavi:

Gymn. crenulatus (Turn. Lin. Tr. VI. p. 130) fronde cæspitosa plana dichotomo-flabellata, segmentis linearibus secus totam marginem incrassatam minute crenulatis, terminalibus o,tusiusculis, nematheciis hemisphæricis in utraque pagina subseriatis.

Ad Oporto, Hb. Turner! ad San Sebastian, Lange!

\section{Dumontieæ.}

Sådan denna grupp uppställdes i Species Algarum, utgjordes den af några få slägten, som icke annorstädes lämpligen kunde placeras. Den ena af dess afdelningar, Chylocladieœ, hörde icke väl tillsamman med Chondriex; den andra, Du- 
montiea, icke med Halymeniex, med hvilka de förut hlifvit sammanförde. Jag antog att cystocarp-frukten hos dem båda hade mera öfverensstämmelse med Rhodymenieernes. Men jag uttalade att jag ansåg hela gruppen till sin begränsning ännu obestämd. $0 \mathrm{~m}$ ock man i afseende på vissa slägten torde i dag kumna dömma med mera säkerhet, kunna dock åsigterne ännu vara delade så väl i afseende på flera af slägtenas aftinitet sins emellan, som i afseende på lämpligheten att uppställa dem i en enda eller flera skiljda, men närslägtade, grupper.

I afseende på Rhabdonia anmärktes redan i Species Algarum att cystocarpfrukten hade en afvikande structur. Sedan man numera känner några andra slägten med liknande cystocarp-frukt, torde dessa kunna lämpligare placeras i en särskilt grupp. Champia torde kumna hänförus till Rhodymenieæ, sedan Chrysymenia och andra slägten med tubulös frous bland dem funnit plats. Att Chylocladia borde uteslutas har visserligen blifvit med mycken bestämdhet yrkadt af Thuret och några andra systematici; jag är också öfvertygad att kapselfrukten väsendtligen atviker från de andra slägtenas. Men det torde vara ganska svårt att uppgifva hvilken lämpligare plats bör tilidelas detta slägte. I sitt sednaste arbete (Synopsis öfver de australiska algerne) ställde Harvey Chylocladia näst efter Halymenia, hvilket, efter min uppfattuing af cystocarp-frukten, torde vara ännu miudre berättigadt. Slägtet Halosaccion, som i Species Algarum upptogs närmast Rhabdonia, kan, så länge cystocarp-frukten ännu är obekant, svårligen till sin atfinitet bestämmas. Af de slägten som hänfördes till Dumontiex återstå således endast Dumontia och Catenella. Nen måhända kunna numera några audra slägten ställas i närhcten af dessa; sådane äro Tichocarpus Rupr., Endotrichia Suring., som torde draga med sig Gloiopeltis och Pikea Harv. Widare torde det kunna ifrågasättas om icke Lomentaria och Polyides, hvilka hvardera halva sin egendonliga, från andra afvikande cystocarp-frukt, böra ställas i närheten af Dumontiex, såvida icke de suarare böra betraktas såsom förhållande sig till -Chondrieerne ungefär såsom Rhodymenieerne till Sphærococcoideerne.

Enligt min uppfattning skulle Dumontieerne vara närmast beslägtade med Rhodymenieerne. Likasom hos dessa äro gemmidierne pressade mot hvarandra inom ett mucöst hylle och blifva derigenom till sin form oregelbundna och kantiga. De synas utg̣̊̊ ifrån en basal eller central placenta, hvars grenar, eller utsprång, ombildas och smälta samman till nucleus. Men i stället för att Rhodymenieernes placenta är grenig, bildande liksom en panicula, hvars skiljda lober successivt utvecklas, så är Dumonticernes placenta vida mindre utvecklad, nucleus blir mindre, och delas icke i flera successivt utvecklade lober. Då hos Dumontieerne frukten icke upptages inom 
ett serskilt pericarpium, utan bildas inom nästan ometamorphoserade grenar, der deremot talrika enkla nuclei ofta äro samlade på vissa ställen, så kunde már nästan antaga, att dessa agglomerationer af enkla inuclei motsvarade de skiljda lober, som hos Rhorlymenieæ äro förenade på en gemeusam placenta. Dumontieernes frukt kunde således betraktas såsom en lägre utveckling af Phodymenieernes.

Gloiopeltis, Endotrichia och Pikea skilja sig från de andra slägtena deruti, att den tubulösa frons omsluter en central, starkare cellrad - en tråd, från hvilken alternerande grenar utgå för att bilda det vittre lager, som omger frons. Gloiopeltis och Endotrichia utmärka sig framför alla andra alger genom den hastiga upplösningen af frons, då den, forut torkad, åter lägges $\mathrm{i}$ vatten. Citom de af Harvey och Suringar beskrifna formerne från Japan, torde Dumontia dura Rupr. Alg. ochot. p. 310 från Kamtschatka böra hänföras till Gloiopeltis. Men det torde ämu vara mycket svårt att afgöra hvad som är art eller varierande form inom detta slägte.

Pikea Harv. Ner. Bor. am. p. 246; Cryptosiphonia I. Ag. mscr. in Hb. Gray.

Frons teretiuscula ramosa gelatinoso-carnosa, juvenilis tubulosa, adultior subfareta, filis articulatis tota constituta; axili siphone ampliore articulato-flexuoso, alterne excurrente in ramos poly-dichotomos corymboso-fastigiatos, demum stratum periphericum continuum, filis brevibus moniliformibus contextum formantes. Cystocarpia in ramulis subpropriis evoluta, immersa et solutione partis fertilis demum liberata, nucleis simplicibus constituta; nucleus ad fila interiora polychotoma suspensus, obeonicohemisphæricus, genmidiis majusculis obovatis, mutua pressione angulatis, a placentula radiantibus, singulis sacculo hyalino inclusis, constans. Sphærosporæ in ramulis numerosæ, eruciatim (ni fallor) divisæ.

Genus mihi videtur ex una parte cum Polyide, ex altera cum Dumontia comparandum. Ut in Polyide sunt gemmidia matura singula saceulo hyalino inclusa; transverse secta, mutua pressione, angulata adparent; longitudinaliter posita sunt fere obconica, ex articulis paucis, vices placentæ gerentibus, provenientia, omnia dense conglobata, pro magnitudine plantæ magna, quasi sulstantia granulosa. I'ræesentia tubi axilis cum Heringia et Desmia, cum Areschougia et Erythroctonio, cum Dasyphlæa et Gloiopeltide, sel præcipue cum Endocladia, genus convenit. Rami nimirum intra frondem tulbulosam (magis juvenilem) laxius dispositi, a tubo centrali sape geminati, patentes, nec nisi in fronde adultiore siphonem centralem proxime prementes, di-polychotomi; ramulorum alii articulis cylindraceis ad periphericum stratum excurrunt, alii articulis moniliformibus, fere latioribus quam longis, constituti eystocarpia ambiunt.

Species mihi sunt: 
1. P. californica Harv. Ner. Bor. am. p. 246 et Vol. III. tab. 49 B.

2. P. Foodii (I. Ag. mscr.) fronde gelatinoso-cartilaginca terefiuscula, ramis quoquoversum egredientibus lateraliter ramosa, ramulisque brevibus, hic illic densioribus subfasciculatim obsita, cystocarpia gerentibus clavatis verrucoso-subspinescentibus. Cryptosiphonia Woodit I. Ag. in Hb. Gray.

Ad Insulam Vancouver.

3. P. Grayana (I. Ag. mscr.) fronde carnosa teretiuscula filiforni, ramis quoyuoversum egredientibus lateraliter ramosa ramulisque brevibus sparsis patentibus virgata, cystocarpia gerentibus fusiformibus utrinque longe attennatis. Cryptosiphonia Grayana I. Ag. in Hb. Gray.

Ad Insulam Vancouver.

P. Grayana est atropurpurea et chartxi vix adhærens, adspectu cujusdam Chondriæ tenuissimæ, dum P. Woodii magis Ch. dasyphyllam amulari diceres.

\section{Dumontia.}

Speciem unicam hujus generis, diu omnibus coguitan, Europxam et boreatem etiam in mari antaretico obvenire statuerunt. Specimen admodum incompletum, Dumontix filiformis nomine inscriptum, vidi plantæe e Nova Zelandia, quam speciem diversam, ne dicam diversi generis, suspicor. Europæa est glutinoso-gelatinosa, et semel collapsa ægre reviviscens; Nov-Zelandica est elastico-gelatinosa, avide aquam imbibens et facile extensa, filis strati interioris stellatim densius anastomosantibus, corticalihus magis exolutis tenuioribus, sphærosporas minores et fere omnino periphericas ambientibus. - Cum multis aliis mihi hoc exemplum est, quan incerta sunt quæ de identitate specierum, in frigidiore hemispherio boreali et australi simul provenientium, prædicarunt.

Tichocarpus. Rupr. Alg. Ochot. p. 320.

Frons compressa linearis dichotoma pinnisque marginalibus obsita, stratis tribus contexta: centrali amplo filis densissime intertextis, intermedio cellulis rotundatoangulatis majoribus, corticali cellulis minutis rotundatis in fila verticalia brevia seriatis. Cystocarpia ciliis inflatis subtubulosis fere in pericarpium mutatis immersa subsolitaria, nucleo simplici constituta; nucleus ad fila interiora polychotoma suspensus hemisphæricus, gemmidiis majusculis obovatis, mutua pressione angulatis, a placentula radiantibus, singulis sacculo hyalino inclusis constans. Sphrerosporæ in apicibus nematheciose evolutis...?

Structura frondis genus cum Prionitide et Thysanocladia fere convenit, fructu ab utroque abludens et cum Rhodymenia magis consentiens; præcipue, ni fallor, cum Pikea congruens. Nucleus juvenilis ad fila interiora in ciliis, hoc tempore tubulosis, 
suspensus, parieti adproximatus, constat filis articulatis a placentula propria radiantibus; subdivisione articulorum fila in lobulos mutantur, quæ intra gelatinam ambientem gemmidia conglobata fovent. In maturo fructu, placenta magis evoluta et ramosa, nucleus gemmidiis quoquoversum radiantibus, a singulis ramis placentæ provenientibus, omnibus in nucleum simplicem confluentibus constat; gemmidia majuscula subseriata et pressione mutua angulata, singula sacculo hyalino inclusa. Nulla carpostomii indicia vidi. Verrucas sphærosporis gravidas, a Ruprechtio descriptas, in spec. ab ipso missis vidi; sed alienas puto et forsan animalis orginis. Apices ramulorum vero nematheciose evoluti nili aliquando obvenerunt; sphærosporas vero cvolutas frustra quæsivi.

Species unica mihi est:

T. crinitus (Gm. Fuc. p. 160) Prionitis? crinita I. Ag. Sp. p. 191. Ticho carpus crinitus Rupr. Alg. Ochot. p. 320 tab. 17.

\section{Rhodymenieæ.}

Till denna grupp hänfördes i Species Algarum slägtena: Cordylecladia, Rhodymenia, Euthora, Rhodophyllis, Plocamium och Wormskjoldia. Såsom osäkert dithörande upplogs slägtet Stenogramma; hvaremot det anmärktes att Fauchea och Epymenia, som blifvit lörut upptagna bland Cryptonemeæ, snarare torde böra hänföras till Rhodymenieæ.

Bättre undersökningsmaterial och en noggrannare jemförelse torde nu tillåta att bättre bestämma gränserne för denna grupp. Slägtet Stenogramma har en olika construerad nucleus och bör utestutas. Euthora och Rhodophyllis torde lämpligare bilda en liten särskild, men Rhodymenieerne nära stående grupp, karakteriserad genom en på annat sät sammansatt nucleus. Deremot torde slägtena Gloioderma, Fauchea, Champia, Chrysymenia, Epymenia och Hymenocladia, samt möjligen äfven slägtet Gloiosaccion, tillhöra Rhodymenieæ.

Hos några af de uppräknade slägtena: Gloioderma, Fauchea, Champia är den inom det yttre pericarpiet inneslutna nucleus omgifven af en apparat af trådar, hvilka, utgående från pericarpiets botten och nedersta delen af placentan, äro fästade upptill innanför mymningen af carpostomiet. Trådarne äro serdeles fina, cylindriska, articulerade och vid lederne genom nästan verticalt utgående grenar sinsemellan förenade till etı i quadratiska rutor sammanhäıgande nät. Denna fina nätlika väfnad 
har utan tvifvel till ändamål att utpressa sporerne genom carpostomiet. Pericarpiet, som till en början är slutet, oppnas småningom, hos Champia nera regelbundet, hos Fauchea och Gloioderma genom en, af trycket inifrån samnolikt förorsakad, springa; det torde vara antagligt att den gelatinösa nucleus sväller upp, då vid oppningens bildande vatten utifrån intränger: då nu den nätlika trådapparaten, som omgifver nucleus, håller emot, så måste följden blifva att den svällande nucleus föres upp mot carpostomiet tills den der brister och sporerne tränga ut. Har den äldsta loben af nucleus sålunda frigjort sina sporer, så torde det vara antagligt att en annan omedelbart derefter börjar samma utvecklingsprocess: hos Rhodymenieerne ser man nemligen ofta, vid basen af den mognande nucleus, några mycket små kroppar, hvilka af Kützing antagas vara egendomliga organer, men som torde kumna anses vara från placentan utgående vngre grenar, hvilka $i$ sin tur komma till utveckling. Man skulle nästan kunna säga att hos Rhodymenieerne uppkommer uucleus från en nästan panicula-lik placenta, hvars öfre grenar först utbildas.

Hos de andra slägtena af Rhodymenieerne finnes icke denna nucleus omgifvande nätlika väfnad: här och hvar synas dock rester af inre trådar, hvilka under en tidigare period förefunnits, men dessa äro enklare, hafva en annan consistens, och torde kunna betraktas som transitoriska bildningar - ursprungligen analoga med de greuar fråu placentan, som småningom ombildas och sammansmälta till sjelfva mucleus.

Om några af Rhodymenieernes slägten torde särskilt böra anföras:

GIoioderma. Detta slägte uppställdes i Species Algarum, hufvudsakligen på grund af en egendomlig structur, som i viss mån erindrar om Gigartina eller Polycoelia. Under ett annat namn (Horea) upptogs samma slägte derefter af Harvey, som dels genom redogörelse för kapsel-frukten, dels genom upptäckten af flera arter, väsendrligast bidragit till kännedomen af detta rent australiska slägte. Det torde nu kunna definieras sålunda:

Gloioderma I. Ag. Sp. p. 243; Horea Harv. Trans. Irish. Acad. Vol. 22 p. 555.

Frons elastico-gelatinosa, compresso-plana, stratis tribus constituta: centrali cellulis rotundato-oblongis laxius conjunctis; intermedio cellulis aut filis anastomosantibus; corticali filis verticalibus moniliformibus, muco facilius soluto cohibitis, constante. Cystocarpia intra pericarpium angulato-cornutum, carpostomio sub-regulari pertusum, nucleum simplicem aut lobatum, gelatina ambiente cohibitum et tela arachnoidea cinctum foventia; nucleus filis gemmidiiferis paniculato-ramosis a placentari plexu Lunds Oniv. Årsskrift. Tom. VIII. 
egredientibus, superne in gemmidia numerosa rotundato-oblonga abeuntibus, constitutus. Sphærosporæ strato-corticali immersæ, sparsæ, cruciatim divisæ.

Structura nuclei Genus ad Champiam et Chrysymeniam arete accedit, tela arachnoidea nucleum ambiente, eximie evoluta, persistente Faucheam referens, structura frondis facilius distinctum. Ob gelatinam elastice dissilientem dissecta pars frondis Gigartinam refert aut Polycoeliam; fructibus vero ab his longius distat.

Genus nomine Gloiodermæ a me ipso institutum et ducente structura frondis, ignoto mihi fructu capsulari, ad Gigartineas relatum; idem dein, nomine Horex, a Harvey conditum, primum inter Gigartinam et Chrysymeniam, demum in Synopsi Algarum Austral. inter Epymeniam et Chrysymeniam collocatum. Mihi Faucher proximum hodie videtur.

Species mihi sunt:

Gl. fruticulosa (Harv. Alg. exs. n:o 440).

G. Halymenioides (Harv. Trans. Ir. Ac. p. 555).

Gl. speciosa (Harv. Alg. exs. n:0 439).

Gl. australis (I. Ag. sp. p. 244) Horea polycarpa Harv. Alg. exs. n:o 438. Obs. Horea Aabelliformis Harv. in Trans. Ir. Acad. p. 555 describitur, nulla posthac mentione de ea facta; mihi hæc ignota, an forma Gl. Halymenioides?

Fauchea. Till detta, genom sin fruktbildning serdeles utmärkta slägte torde böra hänföras en australisk art, som af Harvey blifvit uppställd under slägtet Callophyllis. Åtminstone kau denna art hvarken enligt structuren af frons, eller enligt cystocarp-frukten hänföras till Callophyllis, hvaremot den i båda dessa hänseenden serdeles väl öfverensstämmer med Fauchea. Deremot har den för Fauchea så characteristiska sphærospor-frukten ännu icke, så vidt jag känner, blifvit funnen hos den australiska arten. Genom sina 4-horniga frukter bildar denna liksom en länk emellan slägtena Fauchea och Gloioderma.

Species mihi sunt:

1. Fauch. repens I. Ag. sp. p. 218.

2. Fauch. coronata $=$ Callophyllis coronata Harv. Alg. aust. exs. n:0 406 Phyc. austr. tab. $9 \%$.

Chrysymenia. Till detta, som det synes artrika, slägte torde möjligen böra hänföras Halymenia? digitata Harv. Alg. austr. exs. n:o 436, sedermera i Phyc. austr. tab. 259 äfven med ett ? hänförd till det nya slägtet Gloiosaccion. Till habitus kommer den nära Chr. ventricosa; $\mathrm{i}$ afseende på sphærosporer och structuren af frons ser jag ingen olikhet med Chrysymenia. Men cystocarp-frukten är, så vidt 
jag känner, ännu icke observerad, hvadan artens affinitet icke med säkerhet ännu torde kunna uppgifvas. Äfven det nya slägtet Gloiosaccion (Gl. Brownii), som af Harvey hänföres till Cryptonemex, synes mig komma serdeles nära till Chrysymenia. Kapselfrukten afviker knapt annorlunda än att den är mera insänkt i frons hos Gloiosaccion, mera upptagen inom ett serskilt pericarpium hos Chrysymenia. Hos Gl. Brownii är deremot sphærospor-frukten ännu okänd, och det torde till följe häraf vara omöjigt att ännu med full säkerhet afgöra de till nämnde slägte hänförde arternes ställning i systemet.

Chrys. obovata Sond. lemnar ett serdeles slående exempel på huru farligt det är att bedömma arters identitet efter den yttre formen. Man känner för närvarande åtminstone 3 arter från Australien, soin hafva det egendomliga utseende, som characteriserar den Europeiska Chr. uvaria och gör den så lätt igenkänd bland alla Europeiska arter. Med Chr. obovata bör sålunda hvarken Rhabdonia? globifera I. Ag. sp. p. 355 eller Areschougia Sedoides Harv. förblandas, huru lika till sitt yttre de ock må synas. Till Chr. obovata Sỏnd., som är den af Harvey Phyc. austr. $t a b . X$. framställda, (med uteslutande dock af anförda Synon.) torde möjligen böra häuföras Gigartina ovata Lam. Ess. tab. 4 fig. 7 och möjligen äfven Halymenia Botryoides Ach. Rich. Voy. l'Astrol. p. 145? I Agardhska Herbariet finnes ett af Rob. Brown meddeladt exemplar, som bär namuet Caulerpa Cactoides, skrifvet med Browns egen hand, hvilket är samma Chrys. obovata Sond. Det vill således synas att under namnet Caulerpa Cactoides både den verkliga C. cactoides och Chrys. obovata blifvit förblandade. (Den verkliga Caulerpa Cactoides torde icke vara i något afseende skiljd ifrån Tricladia australis Decs:ne Voy. de la Venus). Sjelf har jag icke varit i tillfälle at undersöka fructificerande exemplar af Chr. obovata.

Cordylecladia. Genom hela sin structur står detta slägte så nära Rhodymenia, att det snarast torde kunna ifrågasättas, om det, oaktadt sin afvikande habitus, derifrån bör skiljas. Från Gracilaria, hvaraf det har habitus, afviker det högst betydligt genom cystocarp-fruktens inre structur.

Species mihi-sunt:

1. C. erecta I. Ag. sp. p. 704 .

2. C. conferta $I$. Ag. ibm.

3. C. furcellata (I. Ag. mscr.) frondibus a disco crustaceo erectiusculis, tercti-subangulatis (exsiccatione angulatis) distanter dichotomis nudiusculis, ramis sparsim constrictis et a strictura proliferis, summis vix tenuioribus obtusiusculis, cystocarpiis ad ramulos hic illic irregulariter dilatatos aggregatis. Gymnogon- 
grus furcellatus Harv. Alg. austr. exs. n:o 295 quoad sp. e Port Phillip Heads (nec G. furcellatus Ag.).

Ad Nov. Hollandiam australem.

Obs. Inter Algas austr. exsiceat. sub n:o 373 Harvey Cordylecladiam? australem habet, quam nusquam ab ipso dein memoratam video. Ex specimine sterili hujus, quod ipsi debeo, vix Cordylecladiam, potius speciem in vicinia Gracil. Confervoides disponendam credidissem. Species præterea mihi dubiæ sunt Cord.? Huntii et Cord.? irregularis Harv. in Ner. Bor. Americ. memoratæ. Plocaria heteroclada Mont. Fl. d'Alger tab. 16 fig. 4 mihi adhue ignota manet.

Plocamium. Sphærosporis zonatim divisis Plocamium a cxteris Rhodymenieis differt, structura fructus capsularis onnino Rbodymeniz: congruum. Placenta, articulis quibusdam validioribus constituta, capsulam intrat; ab articulis inferioribus fila sterilia, longitudinaliter carpostonium versus excurrentia, nucleum ambiunt. Infra lobum nuclei majorem maturescentem sæpe plures minores adsunt, quæ, maturo jam effoeto, suo ordine increscere videntur. Lobus nuclei maturescens gemmidia plurima sat magna, rotundato-angulata, quasi in gelatina suspensa fovet. Sporophylla sphærosporarum quasi ad duos typos quodammodo diversos confecta: nunc nimirum fruticulum plus minus divaricato-ramosum efticiunt, cujus rami clavati aut breviter apiculati sphxrosporas pauciores, duplici serie evidentius dispositas fovent; prout maturescunt sphærosporæ inferiores, prolongantur rami fruticuli et sphærosporæ novæ infra apicem formantur. Sporophylla hæe, dum juniora, sunt ramis abbreviatis eximie stellata. Nunc vero sunt sporophylla jam ab initio leguminiformia, sæpius arcuata, singula fere simplicia sed in ramo, seu stipite communi, plurima conjuncta, quasi fasciculata; ut maturescunt sphærosporæ, hæc quoque prolongantur, formam et dispositionem servantia. Si hæc sporophylla a latere adspiciantur sphærosporæ simplici serie longitudinali, sin a facie conspiciantur duplici serie dispositx adparent.

Species mihi nova, Pl. Hookeri polissimum aftinis, est:

Pl. hamatum (I. Ag. mser.) fronde lineari ecostata decomposito-pinnata pinnis alterne ternis, inferiore maxima incrassata subcircinnatim revoluta, margine superiore inæquali, superioribus densissime decompositis, lacinïs a basi latiore attenuatis subintegerrimis subrecurvis, sporophyllis - - -

Hab. ad insulam Norfolk (Hb. Gray!).

Species e sectione Plocamii admodum distincta, Pl. Hookerii forsan præcipue analoga, diversitate pinnulæ infimæ tergeminarum insignis. Hæc nimirum pinnula in inferiore parte ramorum parum diversa, prolongatur admodum in apicibus incre- 
scentibus, formam fere induens, quam habent rami hamati Hypnearum. Superiore lature - axillam typice spectante, at recurvatione laciniæ exteriore -, pinnula recurvata demum incrassata fit, processubus et lacinulis inxqualis, demum forsan sporophyllis originem datura.

Nomine Pl. affinis Kütz. hane in Hb. Le Normandi inscriptam vidi; at descriptio Pl. affinis Kützingiana (Spec. Alg. p. 884) in nostram, maxime insignem, vix quadrat; et species Kuitzingiana ex Port Natal orta dicitur.

Hymenocladia Cfr. I. Ag. öfuers. af Kgl. Wetensk. Ak. Förh. 1870 p. 449. Species mihi sunt:

1. Hymenocladia lanceolata I. Ag. l. c. Ex insulis Chatam.

2. H. conspersa (Calliblepharis conspersa Harv. in Trans. Irish. Acad. Part. XXII. p. 550. Phyc. austr. tab. 237.

3. I. polymorpha (Rhodym. polymorpha Harr. Phyc. austr. tab. 157).

4. II. dactyloides (Gracil. dactyloides Sond. Harv. Phyc. austr. tab. 80).

๖. H. Ramalina (Gracil. Ramalina Harv. Phyc. austr. tab. 260).

6. H. Isnea I. Ag. Harv. Phyc. austr. tab. 118.

7. I. divaricata Harv. Phyc, austr. tab. XX.

Disponantur

\section{Rhodymeniearum Genera:}

1. Nucleo intra pericarpium subnudo, nunc sparsioribus filis inter lobos excurrentibus instructo, aut residuis filorum nucleum ambientium sparsis munito.

* Sphcerosporis cruciatim divisis.

Fronde tubulosa, cystocarpiis immersis ........... Gloiosaccion.

",$\quad$ aut inferne caulescente, cystocarpïs emersis . . Chrysymenia.

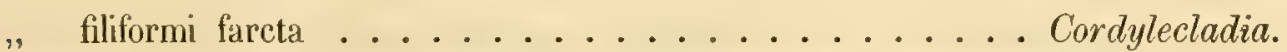

" plana cystocarpiis per frondem sparsis......... Rhodymenia.

$" \quad$ " $" \quad$ in phyllis proprïs ......... Epymenia.

** Spharosporis zonatim divisis

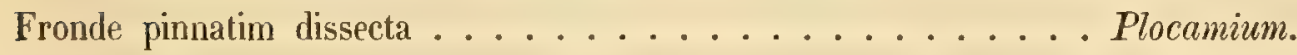

*** Spherosporis triangule divisis

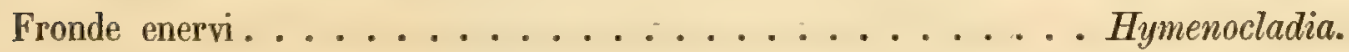

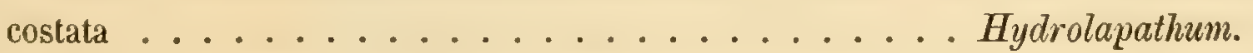


II. Nucleo intra pericarpium circumdato tela arachnoidea, filis tenuissimis reticulatim conjunctis constante.

* Spherosporis cruciatim divisis

Sphærosporis strato corticali fere non mutato immersis ....... Gloioderma. ". in strato nemathecioso superfiliali provenientibus ... Fauchea.

** Spharosporis triangule divisis

Fronde tubulosa diaphragmatibus intercepta .................

Utom de slägten, som ofvanför blifvit räknade till Rhodymeniex, har Harvey dit hänfört en del australiska slägten, som först efter publicerandet af Species Algarum blifvit uppstälde eller åtminstone närmare kände. Dessa äro Erythroclonium, Areschougia och Dasyphloca. Han har derjemte ifrån Dumontieæ öfverfört till Rhodymenieæ slägtet Rhobdonia, som både $\mathrm{i}$ afseende på det yttre utseendet och structuren af frons har en märkvärdig analogi med de förra.

Undersöker man emedlertid nogare structuren af cystocarp-frukten, så torde det visa sig att Rhabdonia icke lämpligen bör sammanföras med de andra slägtena, och att icke heller dessa torde böra räknas till Rhodymenieæ.

Hos de egentliga Rhodymenicerne utgår nucleus från en basal placenta, hvarpå den liksom hvilar, i det den panicula af greniga trådar, som om-metamorphoseras till nucleus, utgår från cystocarpens botten, så att de lober, som successivt komma till utveckling, synas hvila på denna. Hos Erythroclonium, Areschougia och Dasyphlæa är deremot placentan central, $i$ det de fertila trådarne utgå från ett centrum, radierande líka åt alla håll. Hos Rhodymeniex är nucleus enkel så till vida, att den synes samtidigt bestå af en enda, eller stundom kanske ett par fullt utvecklade lober; hos den lilla grupp, som utgöres af de nämnda australiska slägtena, och som vi vilja kalla Areschougiea, är nucleus likasom sammansatt af flera, eller många, åt olika håll radierande lober eller knippen af gemmidier, hvilka sins emellan skiljas genom de enklare, sterila trådar, som utgå från den centrala placentan till den, hela nucleus omgifvande, peripheriska väfnaden och genom hvilka placentan qvarhålles i sitt centrala läge. Då hos Rhodymenieæ analoga sterila trådar förekomma, utgå de från placentan nedanom de fertila loberne och omsluta dessa, under det hos Areschougiex nucleus genom de radierande sterila trådarne likasom delas i en mängd segmenter med ett likasom afskiljdt knippe af gemmidier inom hvardera. Hos Rho- 
dymeniex äro sjelfva gemmidierne slutligen af en mera oregelbunden form, kantiga af trycket emot hvarandra, likasom klumpvis samlade inom det pellucida hyllet, under det att hos Areschougieæ de äro temligen regelbundet aflånga, ordnade i längre rader och bildande likasom knippen af moniliforma greniga trådar. Det synes som berodde olikheten häruti deraf att hos Rhodymenieæ det bufvudsakligen vore de yttersta lederne af de fertila trådarne som utbildade gemmidier, genom ledernes successiva dehning åt olika håll; då deremot hos Areschougieæ de fcrtila trådarne småningom förlängdes under det gemmidii-bildningen fortgick mera $i$ riktning af rudien. Häraf blir en följd att nucleus hos Rhodymeniceme får mera utseendet af en favella; hos Areschougieæ mera af ett coccidium.

Med afseende på den centrala placentan och dispositionen af nucleoli hafva Areschougieæ snarast likhet med Rhodophyllex; men hos dessa hafva nucleoli sina gemmidier till form och läge mera liknande Rhodymenieerne, bildande sålunda radierande lober, inom hvilkas pellucida hylle talrika gemmidier, som ligga hopgyttrade och likasom tryckta emot hvarandra, hafva fătt en mera oregelbunden form; hos Areschougieæ kunna de radierande loberne snarare kallas knippen af greniga moniliforma trådar; de mera aflånga gemmidierne hafva bär, i den mån de bildats, blifvit ordnade i rader och synas sålunda hvardera för sig omslutna af sitt pellucida perisporium.

Utom de redan nämnda torde det till Sphærococcoideerne förut hänförda slägtet Thysanocladia böra hänföras till Areschougieæ. Äfven det af Harvey, under namn af Bindera, uppställda slägtet skulle enligt hans beskrifning och lemnade analyser möjligen böra foras till Areschougiex; men jag har icke sjelf haft tillfälle att undersöka cystocarp-frukten hos Bindera. Af Harvey ställes detta slägte närmast Chætangium.

Den lilla grupp af australiska slägten, som jag föreslår att uppställa under namn af Areschougiex, torde lättare kunna begränsas och definieras, än till sin ställning i systemet med full säkerhet bestämmas. Cystocarp-frukten visar nemligen med afseende på gemmidiernes utscende och disposition icke så ringa analogi med Sphærococcoideerıe, under det att gemmidiernes bildningssätt snarast torde böra jemföras med Rhodymenieernes, utan att fullkomligt dermed öfverensstämma. Men tages Spyridieernes och Rhodophylleernes fruktbildning jemväl med vid jemförelsen, torde det kunna antagas att Areschougieerne böra anses såsom en annan länk i den serie, som i Species Algarum betechnades med benämningen Nematospermeæ.

Man torde alltså kunna definiera den nya gruppen sålunda: 


\section{Areschougieæ.}

Frondes inarticulatæ, aut tubulosæe et tilis sparsioribus percursæ, aut farctæ et strato medullari densiore instructæ. - Cystocarpii nucleus quasi nucleolis plurimis radiantibus compositus, nempe fasciculis pregnantibus filis sterilibus invicem separatis; placenta in nucleo centralis, suspensa filis sterilibus circumcirca an plexum periphericum, nucleum ambientem, excurrentibus; fila gemmidiifera a placenta circumcirca radiantia, moniliforniter articulata, ramoso-fasciculata, inferne gemmidia seriata, superne conglobata sensim radiata, oblonga foventia.

Nucleo quasi nucleolis plurimis radiatim circa placentam centralem dispositis a Rhodymenieis -, quarum nuclei evoluti simpliciusculi aut paucis lobis constantes supra fundum placentarem nidulantur - Areschougiex abludunt; hac vero nuclei compositione cum Rhabdonia, Spyridieis et Rhodophylleis tere convenientes. Nucleoli filis ramosis fasciculatis constituti adparent, gemmidiis intra fila moniliformia seriatis oblongis; fila autem invicem non libera, ut in Sphærococcoideis, sed muco cohibita. Gemmidia, ni fallor, subdivisione nuclei orta, non conglobata et mutua pressione angulata manent - ut in Rhodymenieis norma est - sed prout formantur et separantur invicem, nucleoli obconici in fila fasciculata prolongari videntur, et gemmidia dispositionem radiatam offerunt. Fila sterilia, si quidem in Rhodymenieis adsunt, nucleum aut nuclei lobos a basi placentix carpostomium versus ambiunt; in Areschougicis nucleolos invicem separant. Hoc modo Areschougieæ nucleo composito et nucleolis radiatim circa placentam centralem dispositis cum Rhabdonia et Phodophylleis; formationis modo gemmidiorum et gemmidiis muco cohærentibus cum Rhodymenieis; dispositione vero gemmidiorum seriata cum Sphærococcoideis analogias offerunt; atfinitate et naturali uexu potissimum Spyridieis et Rhodophylleis, adproximandæ videntur, membra, ni fallor, constituentes seriei, quam nonine Nematospermearum in Speciebus Algarum condidi. Areschougieis adnumero Dasyphlcam Harv. (an Mont.?), Erythroclonium, Areschougiam et Thysanocladiam; an Bindera Harv. huc pertineat, dubito.

Dasyphlaa. Det synes mig böra ifrågasättas om Harveys Dasyphlæa är samma slägte, som af llontagne först uppställdes under samma namn. Dels synes det icke af Harveys uppgifter, att han jemfört exemplar af den Montagneska algen; dels torde den af Montagne lemuade beskrifningen och analysen icke lemna nog data tör ett säkert omdöme om det nya slägtet. De microscopiska hår, hvarmed han såg ytan beklädd, hvilka både af Montagne ansågos såsom hufvudcharacter för slägtet och af Harvey tyckas hafva antagits såsom nog characteristiska för detsammas igenkännande, återfinnas hos andra alger - så t. ex. hos arter af Mychodea. 
Äfran förekommer ett vch amuat $i$ den af Montagne lemute beskrifuingen, som snarare torde antyda en Mychodea ("rami truncati ex apice proliferi") än det Harveyslia slägtet Dasyphlca. Montagne har nog sett zonat-delade sphxrosporer, och sårlane förekomma ock hos Mychodea i ctt nematheciöst lager, ehuru man icke gerna här kan tala om nemathecier. Skulle det risa sig att Dasyphlaa tasmanica har sphxrosporer delade på annat sätt, så skulle rerlan detta blifva ett uästan afgörande bevis för att Hontagnes Dasyphlaxa är 'n Mychodea och således ett helt amnat slägte än Harveys Dasyphlaxa.

Erythroclonium Sond. Det ä nästan endast genom habitus, som detta slägte torde kumna skiljas från Areschougia. I yttre form har åter dess arter den största öfruensstämnelse med Rhabdonia, hvarifrån det dock vida mora afviker genon sin frons genomgående, axila siphon, och olika structur af cystocarp-frukten. En u!̣ art, som jag àtminstone tills vidare måste hänföra till Erythroclonium, gör analogierne mellan dessa slägten ännu mera påfallande.

Erythr. pyriferum (I. Ag. mscr.) froude juvenili apicibusque ramorum moniliformiter constrictis subtriquetris, alultiore ranisque majoribus continuis teretiusculis, circumcirca obsitis ranulis obovoideo-pyritormibus, demum subracemose seriatis. An Areschougia sedoides Harv. Phyc. austr. tab. 11\%?; cui certe nostra simillima. Nostram diversam judicavi, quum Harvey ramos minores moniliformiter contractos non memoravit. Vec structuram in nostra cum icone Harveyana omnino congruentem vidi: nostra in caule inferiore habct fila interiora dense in reticulum conjuncta circa tubun centralem, filis corticis verticalibus longi maximam partem constituentibus. In ramulis pyriformibus stratum corticale multo angustius vidi quam in icone Harveyana arlpareat. Nostram, errore quodan, ut specimen fructiferum Trigeniæ australis ex nova Hollandia oecidentali distributum accepi. - Areschougia sedoides Harv. nullum specimen authenticum comparare mihi licuit.

Areschougia Harv. (mut. limit.). Suadentibus aliis generibus - Chrysymenia, Phabdonia - in quibus analogx specierum differentix adsunt, Areschougiam et Erythroclonium in unum Genus conjungere propensus fuissem. Adest tamen prater differentiam habitus, levis quadam in structura fructus diversitas, quæ quid significet mihi adhuc obscurum manet. In plexu nimirum nucleum ambiente Areschougix, prater tila anastomosantia intertexta, adsunt cellula breviores endochromate colorato et diviso instructa. Ipsum nucleum, (intra plexum ambientem) similimum ei vidi, quem in Erythroclonio observavi. Species mihi sunt:

* Fronde teretiuscula quoquoversum ramosa, cystocarpiis in fronde circumcirca nodoso-intumescente immersis. 
1. Ar. dumosa Harv. Phyc. austr. tab. 282.

2. Ar. congesta (I. Ag. mscr.) elatior caulescens, sursum sensim tenuior, fronde teretiuscula yuoquoversum ramosa, supcrne subcorymbosa, inferne ramulis minoribus subseriatis obsita, ramis majoribus erecto-patentibus basi vix attenuatis, ramulis patentioribus, ultimis demum leviter utrinque attenuatis.

Nova Hollandia australis (F. Mueller).

An Areschougia Gracilarioides Harv. Phyc. austr. Syn. n:0 528? Comparandus quoque Fucns congestus Turn. tab. 179, hucusque omnibus obscurus, qui an hujus specimen elotum sisteret duhito. Præterea haud scio an omni statu a sequente specie diversa sit.

3. Ar. Laurencia Harv. Thamnocarpus Laurencia Hook. et Harv.

** Fronde ancipite lineari, subdistiche a margine ramosa, cystocarpiis submamillceformibus supra paginam eminentibus.

4. Ar. Stmartii Harv. Fl. Tasm. p. 321 et Phyc. austr. tab. 294.

3. Ar. ligulata (Harv. mscr.); postea Ar. australis Harv. in Trans. Ir. Acad. p. 554 et Phyc. austr. tab. XIII. (exclus. synon.).

Variat angustior et latior, serraturis marginalibus paucis aut pluribus, pinnulisque obtusioribus aut acuminatis. Halymenia australis Sond. est, me judice, planta simillima, non vero eadem; exsiccata hæe est magis cornea et textura densiore prædita, cxterum Phacelocarpi aut generis proximi specics, nullomodo Areschougia. Specimina Sonderiana planta a Harvey cum formis Areschougia conferta distributa fuerunt. Hine nomen Ar. ligulatæ et primitus datum ot omni respecta aptius restituendum puto.

*** Fronde teretiuscula, ramentis obovatis obsita.

6. Ar.: sedoides Harv. Phyc. austr. tab. 117. - Specimen hujus non vidi, nisi cum Erythr. pyrifero I. Ag. identica esset. Caute cæterum a conformibus distinguenda.

Thysanocladia. Structura cystocarpii Genus mihi videtur Areschougiæ proximum. Nucleus revera in strato medullari suspensus, licet, frondis fertili parte intumescente, pericarpium externum adpareat et carpostomium evidens demum adsit. Placenta, non basalis, sed in medio nucleo centralis, ramosa, fasciculos fertiles quoquoversum emittens, et inter-jacentibus filis sterilibus cum plexu peripherico ambiente conjuncta mihi adparuit. Nucleus hoc modo compositus, a lobulis plurimis radiantibus formatus; lobuli sensim in fasciculos mutantur, in quibus gemmidia minuta rotundata, quasi in fila seriata, observantur. Intra articulos singulos gemmidia plura 
formari videntur. - Ab Areschongia differt genus defectu tubi axilis. - Duas sectiones generis distinguere licet:

* Fronde requlariter pinnatim decomposita, pinnis oppositis utrinque singulis, pinnulis ultimis dentes plus minus acuminatos gerentibus.

1. Th. serrata Harv. Alg. Exsicc. Friendl. Is. n:o 34.

2. Th. dorsifera (Ag. sp. p. 372) Harv. Ner. austr. tab. 35 .

3. Th. costata Harv. Trans. Ir. Acad. vol. 22 p. 550.

4. Th. coriacea (Sond. Bot. Zeit. 1845 p. 56) Harv. Ner. austr. tab. 36.

* Fronde juvenili regulariter pinnatim decomposita, pinnis oppositis sensim in axilla novas generantibus demum fasciculos oppositos formantibus, pinnulis ultimis integris, nunc dente obtuso vel lacinia conformi hic illic obsitis.

ว. Th. laxa (Sond. in Linn. vol. 25 p. 689) Harv. Phyc. austr. tab. 211.

6. Th. oppositifolia (Ag. sp. p. 294) Harv Phyc. austr. tab. 18\%. Th. pectinata Grev. et Harv.

\section{Desmiospermeæ.}

Under denna benärnning sammanfördes i Species Algarum, med någon tvekan, 4 grupper: Helminthocladea, Hypneacee, Chatangiea och Gelidiea, hvilka i afseende pi̊ placentationen syntes sins emellan temligen olika, men som tycktes öfverensstänma i afseende på gemmidiernes beskaffenhet och utseende. Harvey, som i allmänhet adopterat det af mig följda systemet, men som ansett att mera vigt bordt läggas på tillvaron af ett uthildadt pericarpium, skiljer Helminthocladeæ från de öfriga grupperne, och sammanför deremot dessa under benämningen Gelidiaceæ. De olikheter, som förekomma, synas mig dock nog stora att berättiga särskiljandet af de af mig föreslagna grupperne, helst det sedan bekantgorda materialet af nya slägten knappast har medfört någon betydligare utjemning af de antydda olikheterne. I afseende på gruppernes begränsning torde deremot några ändringar böra företagas, då dels nya slägten tillkommit, dels bättre material tillåtit noggrannare analyser af de förut kända.

Jag anser mig dessutom böra bland Desmiospermeerne upptaga en serskild grupp Solieriea, bildad för slägtena Rhabdonia, Solieria Euchema och ett nỵtt slägte Meristotheca, som nedanför characteriseras. 
Det är tillräckligen bekant att bland Algerne många arter antagas vara geme:lsamma för de mest trăn hvarandra skiljda localer. Således antagas mång̨a Europeiska alger jemvä förekomma vid kusterne af Nya Holland. Ctan at liunna forrneka att detta är förhållandet med många, tror jag dock att en nngare jemforelse skall visa att många af dessa, såsom identiska med Europeiska arter ansedda, extracuropeiska former äro tylligt och ofta ganska mycket afvikande. Jagg har nedanför bland Delesserierne antört flera cxempel härpå; ett af de mest slaende är en nyholländsk form, som Harvey ansetl identisk med den af ådder kända Scinaia furcellata, men hvilken, med den största yttre habituela likhet, har en helt annan inre structur, som fordrar dess särskiljande som eget slägte. Ar detta fallet, så torde denna Alg visa med huru myeken varsamhet man måste upptaga deu ofta upprepade satsen om Algernes stora utbrednings-areer, och de consequenser man deraf velat draga. Det nya slägtet torde sålunda kunna definieras:

Gloiophlaea I. Ag. mser.

Frons cylindrica gelatinoso-memhranacea dichotoma immerse costata stratis fere Iribus contexta: axis filis fepe inarticulatis dongatis simpliciuseulis laxe intricatis in columnam medullarem, extra hane sparsiorihus ad stratum periphericum ohlique excurrentibus, infra hoe paulo densioribus, fila peripherica moniliforniter articulata dichotomo-fastigiata, muco laxiori cohibita, lacillime secedentia, sustincutibus. Cystocarpia intra stratum peripherieum suspensa, nucho globoso filis ambientibus densissime intertextis clauso, carpostomium versus aperto, constituta; fila gemmiditera plurima fasciculato-fastigiata, a placentari plexu unclei radiantia, articulato-clavata, gemmidia minuta rotundato-obovata evolventia. Spharospora - - -

Genus Scinaix ut videtur proximum, habitu ita simile ut specimina nomine Scinaid furcellate a Harvey distributa fuerint, structura frondis interioris et fructu capsulari ita quoque conveniens, ut in specichus proximis vix major sit congruentia. Stratum vero periphericum frondis ad omnino diversum typum confectum. In Gloiophlaa nimirum sunt tila peripherica opuntiaformia, articulis contractis constituta, infra apicem articuli umbeilam articulorum conformiun emittentia, terminalibus articulis angustioribus sub-claratis, ommibus muco ambiente cohibitis. In Scinaia, contra, celInle strati peripherici $3-6$ agone angulatx in stratum continum firmiter concreseunt. Gloiophlæa itique quoad structuram Helminthocladeis propinquior. A generilus horum structura tamen et pracipue fructu capsulari abunde differt. In Gloiophlæa fila interiora omnia (axilia, quæ ad stratum periphericum excurrunt et infraperipherica) sunt (jusdem naturæ, nempe tenuissima, tubo endochronate interiore colorato percurso, articulis fere nullis conspicuis; axilia columnam centralem efficiunt, 
filis sub-liberis laxe inter alia positis; oblique excurrentia ita laxa, ut fronden reddunt tuhulosam; stratum infra-periphericum filis paulo densioribus, monpe pluribus secus peripheriam excurrentibus et invicem inter-tortis; hac fila infra-peripherirat cum retate sensim densiora tiunt et in frondis parte inferiore stratum sat conspicuum efficiunt; ex his filis infra-periphericis tum fila corticalia extrorsum, tum fila interiora introrsum excurrunt. Qua quidem structura frondis Genus potissimum Vemalioni adproximari videtur. Fructus capsularis vero est omnino Scinaix; nucleus nempe ambiente intricato plexu filorum introrsum clausus, extrorsum tilis in carpostomiun quodam excurrentibus apertus, fasciculun densissimum filorum pregnantium intra anbientem plexum fovens. Interiore latero ambientis plexus fila gremmidiifera quasi a plano placentari proveniunt, sunt maximopere subdivisa et fasciculatofastigiata, extrorsum radiantia, gemnidia minutissima foventia. - Structura fructus capsularis genus cum Yemastoma, qux structura consimilis cuidam vilerefur, comparare' vetat.

1. Gl. Sciuaioides (I. Ag. mscr.) fronde gelatinosa cylindracea suberuali dichotomodecomposita fastigiata, (exsiccatione collabente); ramis superioribus tenuioribus, apicibus obtusis. Scinaia furcellata Harv. Alg. austr. exs. n:o 348 (non Turn.) quoad spec. e Western Port.; — an omnis Sc. furcellata australis huc pertineat?

Nov. Hollandia.

His de novo Genere dictis, pauca quoque de Scinaia addere placet, ut differentia melius eluecat. Quamquam enim historia speciei vulgaris a pluribus hujus avi algologis illustrata fuerit, hxe tamen nullo modo omuibus uumeris ahsoluta censeatur. De Scinaia salicornioide scribens (Sp. p. 4.23), de cellularum strato exteriore monui, quod mihi in hac specie ita abnorme adparuit, ut speciem allatam hanc ob rem mihi maximopere quod affinitates dubiam haberem. In specie primaria et vulgari hoe stratum non videram, nec. illud antea alii viderant. In Florula Finisterræ, a cel. Crouan edita, in specie vulgari hoc rite indicatum video et in Tab. Phyc. Kützingii in alis formis generis expositum. Periphericum froudis stratun revera constat duplici serie cellularum; interioribus nenpe, qux quasi apicibus inflatis filorum interiorun constant, verticaliter in fronde longioribus, rotundato-angulatis, endochromate evidenti coloratis, extrorsum concrescentibus, et a superficie externa hexagone-angulatis. Ha externe teguntur cellulis subprismaticis verticalibus, dense adproximatis, endochromate conspieuo nullo feré hyalinis. Caterum dissentiunt de structura nuclei, quem Montagne membrana tenerrima diaphana, tenuissime punctulata vel areolata areolis hexagonis ciuctum descripsit. Neque a Harvey, nec a Kützingio indicatam, nec ipse hanc 
membranam videram. Hontagne dein in Sylloge p. 437 eandem adesse contendit, auctoritate fretus Thuretii; et Cel. Crouan eandem ita perspicuan pingunt, ut de illius præsentia dubitare vix liceat. Ipse, contra tantam auctoritatem, presentiam membranæ dictæ denegare non audeo; ingenue autem confiteor me iteratis observationibus illam nec hodie observare valuisse. Nucleum filis strati interioris circum-ambientibus densissime intertextis cinctum video, modo fere eodem quo multa alia genera (Chxtangium, Areschougia, Erythroclonium) uucleum suspensum anbientilous filis tectum gerunt; hec fila circa nucleum, carpostomium versus, excurrunt, ut hoc a Kützingio in Tab. 73 Phyc. gencralis jam pingitur. Fasciculus filorum prægnantium ab hoc plexu quoque oritur, latere a carpostomio remoto; et fila ambientia intricata, quæ nucleum tegunt, vix aliter consideranda mihi adparent, quam quæ in Helminthocladeis nucleum ambiunt. Sunt tantum in Scinaia plurima et intricata, quod ab ipso situ nuclei et natura filorum interiorum pendeat.

Inom slägtet Gelidium anser jag mig böra fästa uppmärksamhet på ett par nya arter:

Gelidimm australe (I. Ag. mscr.) fronde ancipite aut teretiuscula purpurascente tri-quadri-pimata, pimnulis a basi angustiore dilatatis linearibus integerrimis sæpius acuminatis, fertilibus simplicibus plurimis, sphærosporas foventibus lanceolatis, utrinque eximie attenuatis, diclinidia gerentibus evidenter mucronatis.

Ad Novam Hollandiam.

Hæe forma nomine Gel. asperi a Harvey distributa fuit. Verum autem G. asperum Hert. est revera longe diversa planta, Gelid. glandulafolio Hook. et Harv. proxima, si non identica. Utrique characteristicum videtur sphærosporas in pinnellis proprie ad id evolutis ciliformibus demum provenire. In G. australi fructus sunt magis Gelidii cornei, cui in plurimis ita sinile, ut dubium sit an jure specie distinguatur. Fructus facilius evolvantur et numerosiores proveniunt, quasi a propria serie pinellarum conformium formati, magis utrinque acuminati.

Gel. lingulatum (I. Ag. mser.) froude ancipite tri-quadri-pinnata, pinnis majoribus denudatis, minoribusque intermixtis simpliciusculis linearibus, juvenilibus argute serratis, adultioribus margine sxpius longe denudata inæqualibus hic illic in pinnulas abbreviatas sphærosporiferas margine serrato-dentatas demum dense decompositas excreseentibus.

Hah. ad littus Chilense.

Una cum Gel. spinuloso et G. Coulteri hxe species ad sectionem Generis pertinet, quæ sphærosporis in pinnellis subpropriis, decomposito-ramosis aut margine spinulosis, provenientibus dignoscatur. 
Ptilophore nomine novum genus, typo Phyll. spisse Suhr, condidit Kützing, quod ipse ad Chætangieas retulit. In Speciebus Algarum novum genus adoptavi, fructu autem ignoto, cum dubio Gelidieis adnumeravi. Inter species a Harveyo ex nova Hollandia reportatas nova adest, quan ille Gelid. proliferi nomine designavit et in Phyc. austr. sub. tab. 204 nitidissime illustravit. Harvey suam speciem intep Gelidium et Suhriam intermediam statuit. Me judice liæe est mera species Ptilophoræ; structuram frondis saltem omnino convenientem video. Quum igitur in nova hac I'tilophoræ specie eystocarpia cognita sint, nulla de affinitatibus Generis dubia mainent. Quod igitur antea suspicatus sum, Ptilophoram Suhrix proximan esse, hoe fructus in nova detecta specie evidentissime demonstrarunt.

Phacelocarpus, Genus Endlicherianum (= Ctenodus Kütz.), a me ad Sphærococcoideas dubie relatum, quo loco Harvey id adhuc retinuit, a Kützingio inter Gelidieas enumeratum fuit. Quamquam hodie cystocarpia iterum iterumque examinare licuit, tamen de affinitatibus certius quid vix statuere auderem. Cum nullo alio genere bene consociatur; inter plura (Gelidieas, Chætangieas et Sphærococcoideas) quasi intermedium. Cystocarpia externa sunt rotundata aut fere reniformia, maxima parte inferiore sterili, superiore ad modum apothecii inter labia pericarpii convergentia poro aut rima hiante. Placenta deplanata, fundum apothecii occupans, fila gemmidiifera plurima, densissime stipata sursum emittens; gemnidia in filis singulis plura, elongata, utrinque truncata. Nemathecia claveformia aut rotundata, in cryptis infra superficiem circumcirca exsculptis sphærosporas parictales oblongas zonatim divisas inter paranemata fasciculata foventia. - Cystocarpia in diversis speciebus quoad externam formam paulisper diversa, sed ceterum structura congruentia. In Ph. Labillardieri sunt fere reniformia, eapsulam Lycopodii Selaginis fere referentia; in Ph. complanato rotundiora; hine rima lunata in illo, poro in hoc hiantia; aperturam claudunt tere margines incurvati pericarpii; in vallecula excavata a fundo plauato fila gemmidifera proveniunt; sunt hæc fila stipatissima, basi angustiora, superne crassiora et gemmidiis instructa. Gemmidia seriata oblongo-cylindracea et fere truncata. Gemmidiis supremis emissis, hæc aliquando supra fila stipata manent. - Nova mihi species est:

Phacelocarpus apodus (I. Ag. mscr.) fronde distiche decomposita pinnis linearibus pectinato-pinnatisectis, ala angustissima aut nulla costam ancipitem marginante instructis, dentibus rachidis ita formatæ latitudinem sua longitudine superantibus planis a basi latiore acuminatis, cystocarpïs _ _ —, nematheciis globosis ad rachidem sessilibus.

Ad Novam Hollandiam australem. 
In Ph. sessili est costa teretiuscula, ala fere omnino nulla, dentes subulati, basi vix conspicue crassiores, memathecia clavato-globosa brevissime pedicellata.

Ad Hypneaceas, forsan ut sectionem distinctam, Endocladia referenda videtur. Adnuente quodammodo structura frondis hoc genus inter Gigartineas in Speciebus Algarum receptum fuit. A Kützingio el Montagneo Endocladia cum Gloiopeltide ad viciniam Caulacanthi ducitur; confitendum quoque esse quandam inter hae gencra structura analogiam. De aftinitate vero Caulacanthi nullam certam, opinionem Algologorum expressam vidi. In Speciebus Algarum hoc genus Hypmex proximm posui. Bornetian describens ine carpit Thurct quod plura genera male interpretalus sim, et mihi vitio vertit quod, ignoto adhue tructu Caularanthi, hoe gemus infelici mam prope Hypneam disposuerim. De Montagneo, qui ante me Fucum ustulatum Hypneas: speciem constituerat, omnino tacet. Ipse Thuret cystocarpia Gaulacanthi ad apicem ramulorum inflata, carpostomio laterali aperta, axi monosiphonio per totan lougitudinem pereursa, gemmidis cirea axem hoc loco incrassatum dispositis, descripsit. Nec vero ex hac deseriptione de affinitate Caulacanthi certius quid elicere auderem; nec ipse dixit quo loco systematis genus melius disponeretur; nee in dispositione Floridearum postea a Thuretio data (in Le Jolis Alg. de Cherbourg) Caulacanthum memoratum video.

In speciminibus plurinis Caulacauthi a me examinatis nulla cystocarpiis instructa hucusque vidi; in fragmento speciminis Herh. Agardhiani fructum unicum et male conservatum tamen deprehendi, ex quo cystocarpia verucxtormia, intra pericarpium inaquale cellulosum clausum nucleolos plurimos, inter fila reticulatim ambientia suspensos, gemmidiis oblongo-angulatis farcios foventia, viderentur. Nec vero nostra cum olservatione Thuretii bene consociatur, nee sequitur utrum inter Gigartineas an inter Hypneacers locum sibi potius vindicet.

In Endocladice specie (Acanthocladia hamulosa Rupr. mscr.) demun cystocarpia bene cvoluta obstrvare mihi contigit, qux hoc genus ad viciniam Hypnex sine dubio revocant. Cystocarpia hujus in ramulis superioribus infra apicem inflatis, ct apice sterili ramoso aut simplici at spimuloso - fere vesiculan coronatam Cystoseira: Myrica revocante - coronatis obveniunt, ramo sterili fere duplo crassiora. Axis frondis centralis cystocarpium percurrit, ef fila ongitudinalia ab axi inferne separata in arcum ad eundem superne revertunt, interjecto spatio tum interiore (inter axem et fila longitudinalia), tum exteriore (inter fila et stratum exteruum), quod filis transversalibus articulatis et geniculatim flexis anastomosantibusque occupatur. Hre fila ubicumque gemmidifera, genmidiis rempe quasi a ramulis minutis filorum transformatis. Fila itaqu vicibus placentæ multiplicis circumcirca ambientis fungun- 
tur; gemmidia quoquoversum flexa - fere diceres, ut brachia in telegraphis quondam usitatis - filis interjecta spatia occupant. Gemmidia sunt clavata aut obovata, aut mutua pressione omnium, plus minus angulata, nulla cellula ambiente aut gelatina invicem cohibita. Quæ tota structura, quantam cum ea Hypneacearum congruit, patet. Alia specimina nematheciis instructa vidi, at in his nullas sphærosporas detegere valui.

Ad Hypneaceas genus Harveyanum Acanthococci in Spec. Algarum retuli, fidens structure cystocarpii in specie, quæ tamen non fuit typica Generis. Postea specimina fructifera Ac. antarctici videre contigit, ex quibus elucet species a me ad Acanthococei genus relatas minime congenericas esse, quantumcumque alio respectu comrenientes appareant. Ex altera parte, ignoto mihi adhuc fructu Generis Mychodex, hoc cum Cystoclonio identicum conjeceram. Conveniunt revera hæc omnia genera habitu, frondis structura et sphærosporis zonatim divisis (in Ac. antarctico sphærosporæ uondum mihi cognitæ), at structura penitiore cystocarpii diversa puto, licet differentix ægre, nec omni statu conspiciantur. Si rite structuram cystocarpii interpretatus sum, quod tamen minime certus contendo, est omnibus Nychodeæ speciebus ea cystocarpii structura, quam ex unica specie fructifera mihi cognita Acanthococco tribueram, h. e. Hypneaceis pertinent et desmiocarpïs predita sunt; dum in Cystoclonio id cystocarpiorum genus adest, quod kalidii nomine designavi. Quæ si ita sint, sequitur Acanthococei genus reformatum a Hypneaceis removendum esse, Mychodeam autem Hypneaceis referri debere. Præterea species numerosas hodie cognitas Mychodeæ examinanti mihi adparuit unam speciem Harveyanam esse cum alia planta Tovæ Hollandiæ a me descripta et ad alium systematis locum, ignoto adhuc fructu, relata identicam. Quæ omnia hodie sequentibus corrigere molitus sum:

Mychodea (Harv. mut. limit. et char.) Frons carnosa aut gelatinosa teretiuscula aut fere plana, stratis tribus contexta, medullari filis elongatis dichotomis et anastomosantibus, arcuatim inter cellulas strati medii magnas rotundatas excurrentibus; corticali cellulis in fila verticalia evolutis constante. Cystocarpia frondi immersa aut hemisphærice lateraliter prominula, intra pericarpium clausum nucleolos plurimos foventia; nucleoli filis reticulatim ambientibus circumscripti, intra spatium rotundatoangulatum gemmidia circumcirca ab ambientibus filis egredientia, pyriformia, singula stipite adfixa, excipientes. Spharosporce frondi immersæ, sparsæ zonatim divisæ.

Species sequenti modo disponere conatus sum:

I. Mychodea (Harv. partim) fronde tereti cellulis strati medii permagnis, aquam avide bibentibus et facile expansis, strati corticalis filis abbreviatis, Lunds Dniv. Årsskrift. Tom. VIII. 
fere cellulas per' unicam seriem verticalem dispositas formantibus, cystocarpiis unilateraliter prominulis aut sub-immersis, pericarpii parte plus minus expansa (demum rupta?) filis verticalibus constituta.

1. Mych. terminalis Hart. Alg. austr. exs. n:o 413 Phyc. austr. tab. 200! Kütz. tab. Phyc. XVI. tab. \%5; Gigartina longipes Kütz. tab. Phyc. IX. tab. 84? Mychodea Mallardice Kütz. ibm XVI. tab. r\%?

2. Hych. membranacea Harv. Alg. Tasm. p. 408 Alg. austr. exs. n:o 412! Kütz. tab. Phyc. XVI. tab. 7\%. - Obs. Acanth. subulatus Pott. I. Ag. sp. p. 438 tantam habet cum Nych. membranacea similitudinem ut eandem speciem facile conjicerem; an errore locus natalis "mare canadense" ei tribuitur?

3. Mych. carnosa Harv. Alg. Tasm. p. 408. Phyc. austr. tab. 142! Kütz. tab. Phyc. XVI. tab 76. Mych. Muelleri Sond. in Lin. (fide Harvey) Ac. acicularis I. Ag. sp. p. 436.

II. Lecithites (I. Ag. sp. p. 635) fronde teretiuscula, compressa aut fere plana, exsiccatione collabente quasi distiche ramosa, cellulis strati medii majoribus aquam avide bibentibus et facile expansis, strati corticalis filis verticalibus elongatis dichotome ramosis-fastigiatis.

* Fronde teretiuscula quoquoversum ramosa fastigiata ramulisque concrescentibus sape intricata, exsiccatione collabente, sape quasi costam immersam monstrante.

4. Mych. pusilla (Dicranema pusitlum Harr. Trans. Ir. Acad. Vol. 22, p.550; Acanthococcus pusillus Harv. Phyc. austr. tab. 266. An a sequente satis diversa?

כ. Mych. fastigiata (Hypnea fastigiata Harv. Alg. austr. exs. n:o 343 et Phyc. austr. Syn. n:0 45\%).

6. Nych. hamata Harv. Alg. austr. exs. n:o 415! Kütz. tab. Phyc. XVI. tab. 76 . Acanthoc. Evingii Harv. Phyc. austr. tab. 141. Lecithites rangiferinus I. Ag. sp. p. 636 (excl. syn.). Sphærosporas generis vidi!

** Fronde compressa subdistiche pinnatim ramulosa.

7. Mych. compressa Harv. Alg. austr. exs. n:0 414 et Phyc. austr. tab. 201! Kütz. tab. Phyc. XVI. tab. 75.

8. Mych. nigrescens (Harv. mscr.) fronde crassiuscula cartilaginea compressa a margine distiche pinnata, ramulis elongatis simpliciusculis, cystocarpiis infra apices ramulorum subspathulatos frondi semi-immersis obtuse apiculatis. - Cum forma antecedentis consistentiam Mych. hamatæ conjungit.

Ad littus, australe Novæ Hollandiæ. 
9. Mych. disticha Harv. Alg. austr. exs. n:0 416. Fl. Tasm. II. tab. 192 A.! M. chondroidea Kütz. tab. Phyc. YVII. tab. 82? *** Fronde plana lineari aut cuneatim dilatata flabellatim expansa.

10. Iych. foliosa (Gymnogongrus foliosus Harv. Alg. austr. exs. n:0 396 et Phyc. austr. tab. 194). Structura frondis et fructus utriusque est hæe species præcedentibus proxima: forsan potius dubitandum an a M. disticha specie distincta sit. - Variat:

Elatior et a margine procipue foliosa: Rhodophyllis sp. Harv. in Alg. austr. exs. $n: 0369$ !

Obs. In specie Nychodex, quam M. membranacex proximam habercm, pilorum adparatum admodum insignem vidi. Fila nimirum strati interioris, inter cellulas rotundatas excurrentia, cuticulam periphericam usque attingunt, ibique quasi nucleolo deplanato terminantur; ex hoc nucleolo pili microscopici singuli proveniunt. Hoc modo insignis est hujus formæ cum Dasyphlæa Montagnei analogia. In eodem specimne ramos majores hic illic truncatos vidi, ramosque ex truncato apice novos provenientes, quod de sua planta quoque memoravit Montagne. Sphærosporas zonatim divisas in strato subcorticali fere nemathecioso ramorum juniorum quoque vidi. De cellulis admodum magnis intermediis Mychodex non loquitur Montagne, at in parte juvenili hæ parum conspicuæ, et in senili parte facilius dissolvuntur, si diutius pars dissecta sub microscopio servatur. In ejusmodi præparata parte fila conservantur diutius et immo conspiciantur facilius. His accedit, Kützingium, qui specimen Dasyphle insignis, a Nontagneo datum, examinavit, structuram frondis Dasyphleæ Cystoclonio convenientem tribuisse; Cystoclonium vero habet structuram Mychodex simillimam. Quæ mihi tantum cognita est Dasyphlæa Harveyi aliam habet structuram, quam cum Cystoclonio comparare vix cuidam placuerit. Ex scriptis Harveyi mihi non liquet an specimen speciei Montagnei ipse examinaverit; num igitur sit conjecturæ locus eum simillimo adparatu filorum deceptum, suam plantam cum Nontagnei identicam habuisse, prætermissa differentia structuræ, quam ex dicto Kützingii subo-

lere forsan liceat? Quæ quidem omnia dicere debui, ut iterata inspectione adpareat utrum Dasyphlæa insignis Montagnei sit revera species Mychodeæ, an, ut hoc hucusque bona fide assumserint, Harveyani Generis Dasyphleæ species. 


\section{Solierieæ.}

Frondes inarticulatx, tubulosx et filis percursa aut farctæ et strato medullari instructæ. Cystocarpii nucleus quasi nucleolis plurimis compositus, nempe fusciculis filorum prægnantium interceptis filis sterilibus; placenta in nucleo centralis, filis intricatis constituta, et excurrentibus filis (sterilibus) simplicioribus ad plexum nucleum circumcirca ambientem suspensa; nucleoli, circa placentam dispositi, fila gemmidiferá peripheriam versus radiantia emittentes; gemmidia in articulis terminalibus evoluta subpyriformia.

Solieriex placenta centrali (nec basali) et nucleo subcomposito Areschougieis fere analogx; filis pragnantibus, ut videtur, tantum in articulo terminali gemmidiiferis, diverse. Filorum pragnantium natura Solieriex ad Desmiospermeas, Areschougieæ ad Hormospermeas pertineant. Gelidieæ tilis gemmidiferis - attamen brevioriuus - cum Solierieis magis conveniunt; in Gelidicis vero placentatio diversa et structura frondis alia. Solierieas igitur ordinen aut tribum proprium, inter Hypneaceas et Gelidicas quodammodo intermedium, constituere putavi. Decidere restat an genera quxdam Sphærococcoideis relata (Dicranema, Heringia, Stenocladia) ad viciniam Eucheumatis potius revocanda sunt. Placentatio in his certe basalis (nec centralis) et fila pragnantia paulo magis Sphxrococcoideis congruentia suadent.

Genera Solieriearum sequenti modo disponantur:

* Spherosporis cruciatim divisis:

Fronde plana membranacea subtubulosa, in papillis capsulifera . . Meristotheca.

* Spharosporis zonatim divisis:

a) cystocarpiis per fiondem sparsis, immersis aut plus minus prominulis: Fronde subtubulosa, aut demum solidescente ramis subtubulosis . Rhabdonia.

b) cystocarpiis in ramulis subpropriis, immersis aut subprominulis: " Fronde farcta, strato medullari immerse costata ........ Solieria.

c) cystocarpiis intra pericarpium sub-proprium externum exceptis: Fronde farcta papillosa, in papilis capsulifera ......... Eucheuma.

\section{Meristotheca I. Ag. mser.}

Frons plana gelatinoso-membranacea laciniata dentibus et tuberculis exasperata, intus tubulosa, tubo filis articulatis anastomosantibusque percurso, peripherico strato introrsum cellulis magnis rotundatis, superficiem versus sensim minoribus, extrorsum cellulis minutis fere in fila brevia verticalia conjunctis, contexto. Cystocarpia in 
tuberculis sita, strato corticali amplius evoluto inclusa, clausa, intra plexum peculiare, arcte ambientem, nucleum compositum foventia; nucleus filis intertextis, a centro ad periphericum plexum extensis, subdivisus, inter filorum columnas fasciculos filorum prægnantium, peripheriam versus radiantes emittens; gemmidia in articulo terminali filorum evoluta, pyriformia. Spharosporce strato corticali immersæ, sparsæ, cruciatim divisæ.

Nucleo composito ex una parte Rhabdoniam et Binderam Harvo ex altera Kallymeniam referre videatur, velut structura frondis cum his Generibus non parum convenit. Situ cystocarpiorum, velut penitiori structura nuclei a Kallymenia admodum differt; In nucleolis Kallymeniæ gemmidia, sine ordine adparente conglobata, peridermate communi cohibentur; in Meristotheca gemnidia in articulis terminalibus singula et pyriformia proveniunt. Sphærosporis a Rhabdonia, præter alias, recedit.

Species mihi sunt:

1. Mer. papulosa I. Ag. mscr. Callymenia papulosa Mont. Alg. Yemens. n:o 21. Syll. p. 438 I. Ag. sp. p. 293; Kallymenia exasperata Zanard; Halymenia ceylaniça Harv. Alg. Ceyl. exs. n:o 30. Kütz. tab. Phyc. 16 tab. 93 (non bona). Summam externam similitudinem cum Halymenia Durvilliei Bory præterea monstrat.

Obvenit in mari Rubro et Oceano Indico superiore.

2. Mer. Duchassaingii $I$. Ag. mscr. fronde plana subpalnatim laciniata, laciniis subcuneatis, margine ubicumque laceris lacinulis conformibus dentibusque, paginaque plana dentibus consimilibus ubicumque exasperata. Cystocarpïs - - Habitus Callophyllis laciniatæ majoris, - sed superficie aspera mox distinguenda.

Ad Guadeloupe D:r Dychassaing legit.

Species hæc forma et divisionis norma fere Call. laciniatam referens, sed major et tuberculis a disco et margine densissime emergentibus facilius distincta. Laciniis his mollibus horridulam speciem Gloiodermæ ( $=$ Horeæ Harv.) fere crederes, at structura omnino diversa. Spherosporas supra descriptas inter fila verticalia frondis evolutas vidi; nullos autem fructus capsulares observare hucusque licuit.

Rhabdonia. Specierum synonymia paulisper intricata, hoc loco species mihi cognitas enumerare placet:

I. Fronde cylindracea aut compressa, subcontinua aut tantum vage hic illic contracta (= Rhabdonia).

a) Cystocarpiis in nedia fronde nidulantibus, circumcirca prominulis, in ramulo subsingulis.

1. Rh. coccinea Harv. Phyc. austr. tab. 54. 
2. Rh. nigresceus Harv. in Lond. Journ.; I. Ag. sp. p. 354. - Nomine Rh. nigrescentis diversæ species venditantur. In originali planta structuram Rhabdoniæ vidi. Specimen inter Algas. exs. Harv. sub n:0 389 distributum, quod vidi, est diversissima planta, quam in Herbario nomine Thamnocarpi Harveyani interim designavi.

3. Rh. dendroiles Harv. Phyc. austr. tab. 152.

b) Cystocarpiis unilateraliter plus minus prominulis, per frondem sparsis.

4. Rh. tenera I. Ag. sp. p. 354. Solieria chordalis Harv. (non Ag.!) Ner. Bor. Americ. p. 121 tab. XXIII A. eximie! Rh. Baileyi Harv.; Kütz. tab. Phyc. 16 tab. 74 .

๖. Rh. robusta Grev.; I. Ag. sp.p. 355. Solieria austratis Harv.; Phyc. austr. tab. 149.

6. Rh. Coulteri Harv. Ner. Bor. Am. p. 154 tab. XXIII. B.

7. Rh. mollis Harv. Alg. austr. exs. n:0 388.

8. Rh. ramosissima; Chrysymenia ramosissima Harv. Ner. Bor. Amer. p. 190 tab. XXX. B.

Obs. Rh. patens Harv. Phyc. austr. Syn. n:o 519 est species mihi ignota.

II. Fronde juvenili ramisque subarticulatim constrictis, ramis quasi prolificatione ortis, ad stricturas emergentibus, sape subverticillatim adproximatis, stricturis in ramis majoribus sensim obsoletis. (Opuntiopsis $I . A g$.).

9. Rh. Charoides Harv. Phyc. austr. tab. 196.

10. Bh. clavigera (I. Ag. mser.) fere tota tubulosa el stricturis regularibus articulata verticillatim ramosa, superne subcorymbosa, articulis caulinis inferioribus prælongis anguste obconicis, superioribus oblongis ovalibusve, cystocarpiis - Erythroclonium sp. nov. Harv. Alg. austr. exs. n:o 392. Habitus fere Erythr. Sonderi, at structura Rhabdonix! Cellulæ corticales majores quam in aliis speciebus. Ad genicula stratum corticale nunc magis evolutum vidi. Species distincta, at adhuc parum cognita e Nova Hollandia, australi.

11. Rh. verticillata Harv. Phyc. austr. tab. 299.

12. Bh. violacea ( $I$. Ag. mscr.) inferne caulescens continua, superne tubulosa consricta, ramis majoribus elongatis continuis, paucis inferne in verticillos collectis, plurimis virgatim ramosis, ramulis ad stricturas sæpe sparsis, basi eximie attenuatis, apice obtusis, cystocarpiis - - C Color hujus fere est Grateloupiæ 
cujusdam, at structuram Rhabdoniæ (tubum filis repletum) videre credidi. Specimina nostra male reviviscunt.

Ad Cap. b. Spei.

III. Fronde juveniti ramisque ultimis subarticulato-contractis, adultiore subcontinua, ramentis simpliciusculis vesicaformibus obsita (BoTRYомоврна $I$. Ag.).

13. Rh. globifera $I . A g . s p . p .355$. Harv. Phyc. austr. tab. 129. A conformibus Chrysymenia uvaria, Chr. obovata, nee non Aresch. sedoide, hæc caute distinguenda. Non suspicata plurium homomorphia, synonyma apud primos descriptores confundehantur. Fucus globiferus Lamour. cum nostra identica videtur.

Species mithi adhuc inquirenda sunt:

Rh. divaricata Forsk.; I. Ag. sp. p. 702.

Bh. dura Zanard. Pl. mar. Rubr. tab. IX. fig. 1. Cum hac forsan comparanda Rh. robusta var. Wigtii I. Ag. sp.

Solieria $I$. $A g$. est Genus Rhabdoniæ certe proximun, et species utrinsque confusæ fuerunt; differt, ut mea fert experientia, in eo quod Solieria haud tubulosa, sed carnoso-farcta; quod in Solieria fructus utriusque generis in ramulis propiis fusiformibus evolvuntur; denique, ni fallor, in eo quod nucleus, filis sparsioribus a placenta centrali: ad plexum ambientem extensis, habeat speciem nuclei simplicis; gemmidia quoque magis pyriformia et evidentius tantum in articulo ultimo evoluta. Solieria chordalis charta parum adhæret, et adparatu radicali fibroso admodum insigni instructa est. Cellula intermedix, tubum Rhabdonix cingentes, sunt sat magnæ et quasi inanes; cellulæ, quæ in Solieria stratum medullare ambiunt, sunt exterioribus quidem majores, at minori differentia, sape quoque granuloso contentu instructæ; eadem fere pericarpii differentia: pericarpium in Rhabdonia cellulis interioribus magnis, sub-duplici serie dispositis, a cellulis corticalibus abruptius separatis; in Solieria cellulæ interiores sunt minores, in exterior's sensim abeunt. Sphærosporæ Rhabdoniæe inter fila verticalia brevissima sunt sparsiores; in Solieria, quia in ramulo proprio obvenientes, inter fila verticalia bene evoluta densiores.

\section{Sphærococcoideæ.}

Sålan denna grupp till sina characterer framstalldes i Species Algarum, torde den fortfarande kunna bibehållas. Nogra nyare australiska slägten, uppställa af 
Harvey (Curdica, Nizymenia) torde jemte det här nedanför upptagoi (Stenocladia) böra tilläggas. Deremot böra Thysanocladia, Eucheuma, Lecithites, Desmia och Phacelocarpus, hvilka nästan alla med tvekan, eller mera provisoriskt hänfördes till Sphærococcoideerne, derifrån uteslutas, sedan bättre material lemuat tillfälle till noggrannare analys af fruktdelarne. För de uteslutna slägtena har jag på andra ställen här närmare redogjort.

I afseende på cystocarp-fruktens structur bör anmärkas, att en olikhet förekommer deruti, att hos en del slägten äro de från placentan utgående trådar, inom hvilka gemmidierne utbildas, korta och klubblika med få gemmidier, utbildade endast inom de öfversta lederne; hos andra slägten äro dessa fertila trådar vida längre, mera perlbandslika och med flera gemmidier, utbildade inom många leder. Flera af' de slägten, son äga de korta klubblika trådarne, hänföras af Harvey till Gelidiaceæ, till hvilka de genom denna structur visserligen närmá sig, men torde dock, enligt min uppfattuing, med mera rätt böra bibehållas bland Sphærococcoidex; och détta med s̊̊ mycket merà skäl som Sphærococcus och Calliblepharis, hvilka nästan böra anses som Sphærococcoideernes typiska slägten, höra till denna afdelning, under det Gracilaria utgör hufvudslägtet inom den andra afdehningen. I den nedauför meddelade uppställningen af slägtena är den nämnda olikheten lag̣d till grund.

Corallopsis. Coccidia vidi fere cum iis Gracilariæ omnino congruentia; pericarpium crassiusculum cellulis interioribus pluriseriatis concentricis, exterioribus radiantilus, in fila brevia verticalia conjunctis. Carpostomium in apice sub-apiculato denum adest. Placenta a fundo elevata cellulosa, cellulis multo minoribus quam cellulæ frondis interiores, constituta, a superficie alterne excavata et producta, atque a cryptis ita formatis fila gemmidiifera ubicumque enittens; gemmidia in filis cryptarum invicem liberis clavato-moniliformibus seriata, termiralia fere obovata.

Species mihi nova:

C. opuntia (I. Ag. mscr.) fronde inferne continua decomposito-dichotoma subfastigiata, ramis superioribus plus minus evidenter articulato-constrictis dichotomis, articulis demun pyriformibus diametro duplo longioribus. Corallopsis cacalia? Harv. Alg. Ceyl. n:o 30.

Ad Ceylonam.

Articulis, sic dictis, multo brevioribus a $\mathrm{C}$. cacalia differre mihi videtur.

Gracilaria. Structuram placentæ, qualem in Corallopsi descripsi, etiam in Gracilaria vidi. De speciebus pauca tantun hoc loco adnotanda:

Grac. fureellata, Harv. Phyc. austr. tab. 286, quæ ramificatione stricte dichotoma et subfastigiata inter Gracilarius dignoscatur, a Plocaria furcellata Mont. 
Alg. Yem. n:o 12, quam cum sua specie identicam credidit Harvey, est revera species diversissima. Habitu quidem una cum altera sat convenit, at stratum axile proprium in Plocaria furcellata Hontagnei adest, cujus præsentia colligere licet speciem maris rubri ad diversum genus pertinere. De hac conf. Dicranema furcellatum I. Ag. infra. Caveas, caterum, ne Grac. furcellatam cum Gymnogongro furcellato Auct. eandem credas.

Curdiea Harv. Cystocarpia vidi in C. laciniata cum is Gracilariæ aut Dicurellæ admodum convenientia, ita ut, adnuente quoque structura frondis, hæ: species Gracilaria admodum propinqua cousideranda sit. Placenta adest hasalis permagna, parum lobata, a vertice et lateribus filis radiantibus gemmidiferis densissimis obsita; fila clavato-moniliformia, invicem libera, gemmidia seriata obovato-rotundata foventia. Sphrrosporæ cruciatim divise bujus speciei sunt in maculis subnematheciosis intramarginalibus sparsis evolutæ; qua nota et levi differentia placentæ Curdiea a Gracilaria distare videtur. Altera species, quam ad Curdieam refert Harvey, est Rhodymenia obtusata Sond., ad quam præterea Gymnogongrum firmum Aresch. Phyc. nov. p. 354 ut synonymon ducit. Nihi haud liquet an ambex species (C. laciniata et C. oltusata) ad idem genus pertineant. Cystocarpia in C. obtusata sunt supra paginam planam hemisphærice-elevata, placenta subhemisphærica, pericarpii cellulis fere omnibus eximie radiantibus. Nemathecia oblonga in medio segmentorum seriata vidit Harvey. Sphærosporas zonatim divisas in suat specie observarit Areschoug, quod genus diversum sine dubio indicaret. Sunt vero in descriptione Areschougï nonnulla, qux in speciem Sonderi non optime quadrant.

Melanthalia. Nirum quod in speciebus pluribus hujus generis frequentibus fructus sphrosporarum hodiedum ignotus manet. Tantum in M. Jaubertiana vidi apices ramorum clavato-incrassatos, spicam Typhæ æmulantes diceres. Stratum corticale his locis eximie evolutum, in fila stipatissima articulata subclavata mutatum. Ad apices filorum spherosporas sensim provenire adparuit, at nec bene evolutas, nec divisas videre mihi contigit. Clavæ nematheciorum sunt in M. Jaubertiana teretiusculæ; in latiore fronde II. obtusatæ vix terctiusculas suspicarer. Fructibus omnium demum detectis, species melioribus characteribus circumscribere forsan liceat.

Calliblepharis. Genus et habitu, et structura frondis, et sphærosporis, sive situm sive divisionis modum respicias, cum Rhodophyllide summam offert similitudinem. Cystocarpiis autem genera facilius distinguantur. In Calliblephari placenta adest basalis, a vertice et lateribus fila gemmidifera plurima clavato-moniliformia, invicem libera, sustinens; gemmidia in articulis superioribus evoluta, sensim deorsum maturescentia; suprema initio pyriformia, sensim rotundiora, membrana articuli hyaLunds Univ. Årsskrift. Tom. VIII. 
lina gemmidium limbo plerumque conspicuo circumdante. In Rhodophyllide placenta centralis, filis sterilibus ad pericarpium extensis suspensa, nucleolos plures, circuncirca dispositos, filis sterilibus radiantibus separatos, gerit; nucleoli filis a placenta centrali provenientibus orti, in articulis superioribus gemmidia conglobata, muco solidescente invicem cohibita, generantes. Calliblepharis hoc modo inter Sphærococcoideas, Rhodophyllis genus Rhodymenieis propinquum videtur. - Licet genera hoc modo abunde diversa adpareant, dificillimum est dictu utrum species uni aut alteri generi pertineant, nisi cystocarpia speciei cognita sint. Hine adhuc incertum videatur an species quædam ad Calliblepharim relatæ, eidem revera pertineant. Callibl. Preissiana, cujus cystocarpia nec a me, nee a Harveyo observata, sec. descriptionem Sonderi species Calliblepharis videretur. A Callibl. ramentacea (Ag. sp. p. 1r'q) I. Ag. $s p . p$. 621, quæ exteriore forma simillima est, illa caute dignoscatur. In C. ramentacea cellulæ interiores duabus seriebus, interjectis minoribus cellulis, dispositæ. In C. Preissiana cellulæ interiores pluribus seriebus dispositx et magnitudine invicem magis xquales. Sua quidem structura C. ramentacea cum Rh. membranacea proxime convenit. Tota serie formarum, quilus hæe species ludit, considerata, magnopere dubium adpareat an jure distinguantur $R h$. membranacea et Callibl. ramentacea. Nihi C. ramentacea paulo firmior substantia, chartx nou adhrens, et segmentis ultimis obtusioribus instructa videtur. Utcumque sit, ob rationes allatas Deless. ramentaceam Ag. ad sectionem Rhodophyllidis (Stictophylli), quæ structura allata dignoscatur, referendam puto; quod quoque in Synops. Alg. austr. Harvey, dubio adposito, jam monuit. Quæ præterea nomine C. conspersa Harv. distributa fuit forma, minime Calliblepharis species mihi adparuit sed Hymenocladia, ut hoc in enumerat. Alg. ex Chatam Insulis (Act. Holm. 18\%0) exponere molitus sum. An, contra, ad Calliblepharem (aut gelus quoddam ricinum?) revocanda sit species, quam nomine Rhodymeniæ proliferæ e Nova Zelandia descripsit Harvey, dubium mihi videtur. Habitus certe non Calliblepharem, sed Rhodymeniam suadet, Rh. palmette proximam. Structura vero frondis et coccidiorum cum Calliblephari fere convenit; a placenta basali elevata fila clavato-moniliformia invicem libera plurima rarliantia. Spherosporas frustra quæsivi; his detectis de genere certius statuere licet. Plantam Sphærococcoideam hoc loco interea memorare volui.

Sarcodia. Novas duas species hujus generis descripsit Harvey. Una, S. ceylanica, cum specie typica generis optime convenire videtur; altera, S. platycarpa (Harv. Alg. exs. e Friendl. Is. n:0 52), mihi potius Halymeniæ species videtur, structura frondis et fructibus, a me visis, cum hoc genere fere conveniens. 
Dicranema. Hařey pluribus quidem locis questionem movit an genus hoc melius inter Gelidia militaret et in ultima dispositione (Syn. Alg. austral.) genus nullo adposito dubio ad suas Gelidiaceas refert. Placentam perietalem ut in Pterncladia consideravit Harvey; mihi structura aliter explicanda adparuit. Cystocarpia nimirum supra unam paginam prominula puto, ut in multis aliis generibus et quidem etiam in Pterocladia; placentá a strato medullari frondis provenit, ut hoc ubicumque quoque norma est. In Gelidio vero et I'terocladia stratum medullare frondis immediate, ut ita dicam, genmidiorum fasciculos sustinet; placenta itaque in Pterocladia est basalis, in ipso fundo cystocarpii stratum expansum planum efficiens; in Dicranemate vero, sectione longitudinali frondis per cystocarpium feliciter ducta, cognoscere licet placentam propriam e strato medullari frondis oblique adscendere; et ex hac alscendente placenta filiformi fila gemmidifera circumcirea, et a vertice et a lateribus, proveniunt. Si vero, sectione frondis transversali facta, cystocarpium in Dicranemate observatur, placenta adpareat basalis si juxta basem, qua a strato medullari frondis surgit, transverse secta sit; sin per superiorem partem oblique adscendentis placentæ sectio ducta fuerit, placenta undique libera conspiciatur. In Pterocladia placentare stratum est frondis strato medullari parallelum; in Dicranemate est placenta strato medullari verticaliter imposita. Mihi Dicranema genus Sphærococcoideum adparet. Species disponantur:

* Coccidiis infra apices ramorum revolutos solítariis.

1. D. revolutum $A g$. $s p$.

2. D. Grévillei Sond.; an a priore sat diversa?

* Coccidiis - in ramorum inferiore parte, unilateraliter nodosa, sape pluribus:

\section{D. filiforme Sond.}

Species mihi dubia:

4. Plocaria furcellata Mont. Pug. pl. Yemens. n:o 12. Axis hujus occupatur tenui fasciculo filorum longitudinalium ut in Dicranemate. Sterilis planta æagre a D. filiformi distingnatur, fructibus tamen ignotis incertum manet an revera Dicranematis species sit. Gracilaria furcellata (Havv. Phyc. austr. tab. 286) haloet structuram Gracilariæ, nec ullo pacto cum specie Nontagnei confundenda. Dicranema furcellatum (Hook. et Harv. Alg. Tasm. p. 9 et Fl. Tasm. p. 313) vix est Dicranematis species; stratum enim medullare hujus generis desideratur. Sterilem plantam hujus tantum vidi. An Ahnfeltix magis propinqua? Nizymenia. Genus a Harvey Gelidiaceis relatum, mihi videtur Sphærococcoideum, et quidem proximum is (Heringia, Stenocladia) quorum fila gemmidifiera 
clavata fere tantum in articulo terminali præcociore prægnantia apparent. Pericarpium crassum constat stratis frondis uberius evolutis; filis anastomosantibus strati medullaris, et verticalibus strati corticalis admodum conspicuis. Centrum placentæ occupant cellulæ quædam transmutate strati interioris, polyedræ, anastomosantes, multo majores; a quibus fila radiantia stipatissima proveniunt; periphericam zonam circa placentam constituunt fila gemmidifera.

Heringia. In structura cystocarpii adnotanda mihi videtur insignis cum Eucheumate analogia. A placenta basali, quæ filis plurilus a tubo axili frondis provenientibus, articulatis, endochromate subclavato percursis, invicem anastomosibus junctis, composita est, exeunt fila sterilia ad pericarpium. Inter hec fila sterilia disponuntur fila gemmidifera fasciculata, quæ ita quasi nucleolos plures elficiunt. Nucleum itaque compositum considerare liceret et genus cum Eucheumate ejusque affinibus comparare. Vihi tamen genus potius Spharococcoideum adparet, suadente placenta basali et filis gemmidiferis, quæ structura ab iis proximorum generum vix abludunt.

Stenocladia ( $I$. Aq. mscr.). Frons compressa distiche pinnata, aut teretiuscula el vage ramosa, stratis fere tribus tubum axilem articulatum ambientibus contexta: medullari filis elongatis articulatis dense intricatis; medio, nunc parum conspicuo, cellulis oblongis laxius dispositis; corticali cellulis minoribus verticaliter seriatis. Cystocarpia externa subsphærica, secus latera ramorum sessilia, intra pericarpium cellulosum, demum carpostomio apertum, nucleum subsimplicem foventia; placenta basalis elevata, filis pluribus a tubo axili provenientibus articulatis et anastomosantibus contexta, et sterilibus filis cum pericarpio juncta, a vertice et lateribus fila gemmidifera fasciculata cylindraceo-clavata, invicem libera, plurima sustinens; gemmidia in articulis terminalibus evoluta, pauca seriata, demum rotundata. Sphærosporse - - -

Genus Phacelocarpum et Areschougiam structura frondis, cystocarpüs Heringiam referens, sphærosporis adhuc ignotis nondum forsan sat stabilitum. A Heringiæ genere proximo, ad quod unam speciem refert Harvey, evolutione majore strati medullaris differt - qua differentia sæpius genera distincta hodie consideramus. Attamen dicere fas est, stratum medullare in fronde juvenili ad tubum axilem fere reductum esse. Hoc modo unam speciem, quæ cellulas intermedias rotundatas gerit, ad Heringiam referre forsan licuisset. Altera autem species, aut forsan duæ, sub hoc nomine conjuncte, quæ cum prima summam sine dubio habent aftinitatem, vix ad Heringiam referrendæ videntur. Hinc genus intermedium speciebus his constituere malui quam idæam, ut mihi adparuit, alienam Heringiæ tribuere. Sphærosporis de- 
mum detectis limites distinctiores ducere forsan liceat. Areschougiam coufertam (Harveyi) nuclei structura ab Areschougix speciebus legitimis longe differre, addere placet. - Duæ mihi sunt sectiones generis et species sequentes:

* Frons teretiuscula, dichotomo-decomposita; frondis intermediis cellulis rotundato-oblongis laxioribus, stratum proprium evidentius formantibus.

1. St. furcata (Heringia furcata Harv. Aly. austr. exs. n:o 311 et Phyc. austr. tab. 215).

Harvey suspicionem movit an hac sit Phacelocarpi quædam forma denudata, nec speciem genuinam constituens. Whi quoque structura cum Phacelocarpo magis quam cum Heringia convenire adparuit, utpote stratum nedullare filis numerosis tubum axilem circumdantibus constat. Fructus autem Phacelocarpi, hodie sat bene mihi cogniti, a fructibus Stenocladiæ furcatæ sphericis, ad latera ramorum penultimorum sessilibus, et structuram supra descriptam ofierentibus, maximopere differunt.

* Frons ex tereti-compressa aut anceps pinnatim decomposita; frondis intermediis cellulis parum incrassatis stratum proprium vix formantibus.

2. St. conferta (Harv. Phyc. austr. tab. 166) fronle compressa ancipite a margine pinnation dense decomposita, pinnis a basi eximie attenuata dilatatis obtusis; variat:

a. Cliftoni fronde inferne teretiuscula, superne compressa et ancipite, externe subecostata, pinnis ultimis basi longe teretiusculis apice spathulato-dilatatis, fructibus - - $\therefore$ Aresch. conferta Harv. partim. Halymenia australis Sond.?

Ad Novam Holiandiam occidentalem.

3. Harveyi fronde ima basi teretiuscula, mox compressa ancipite quasi costa externa elevata instructa, marginibus adultioribus verruculoso-inæqualibus, pinnis ultimis basi eximie attenuatis mox spathulato-dilatatis, cystocarpiis secus margines seriatis sessilibus. Aresch. conferta Harv. Phyc. austr. icon. tab. 166 .

Ad Novam Hollandiam australem.

Plures species, externa facie admodum similes, nomine Aresch. confertæ ab initio confusas fuisse, satis constat. Harvey ipse in operibus posterioribus duas distinxit Nizymeniam nimirum, et Aresch. confertam 1. c. delineatan. Nihi vero minime certum videtur omnem confusionem his distinetis esse sublatam. Duas sub nomine Aresch. confertæ adhuc latentes formas supra indicare molitus sum; unam australis, 
alteram oceidentalis Novæ Hollandix incolam suspicor, sec. specinina mihi obvia. Australis forma summam offert cum Aresch. ligulata externam similitudinem, nisi quod angustior sit; fructus vero admodum dissimiles et situ et structura. Ad formam occidentalem Halymeniam australem Sonderi referendam esse suspicor, quæ, me judice, neutiquam ad Aresch. ligulatam pertinet, ut hoc statuit Harvey.

Spharococcoidearum genera hodie disponantur:

+ Fila gemmidiifera moniliformia, gemmidia seriata, in articulis plurimis evoluta, foventia.

* Frondes ecostatce, stratis duobus cellularum contexte:

Fronde articulato-constricta, nunc inferne continua ...... Corallopsis.

" continua teretiuscula aut compresso-plana, stratis 2:bus constituta:

sphærosporis per frondem sparsis cruciatim divisis . Gracilaria.

" aggregatis certo loco, plus minus nema-

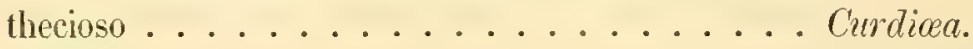

? Acropeltis Mont.

Dicurella.

** Frondes stratis fere tribus contexta:

nematheciis externis ............ Melanthalia.

It Fila gemmidiifera angustiore stipite subclavata, in articulis supremis gemmidia pauciora evolventia.

* Frondes siphone axili destituta.

Frondes planæ, duobus stratis contextæ .......... Calliblepharis.

" $\quad$, , tribus stratis constitutæ .......... Sarcodia. Nizymenia.

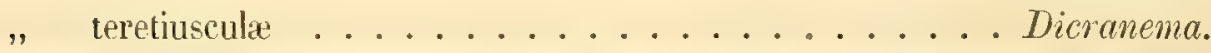

** Frondes siphone axili percursa.

Siphone axili cellulis strati intermedii cincto ........ Heringia.

" ., filis tenuioribus strati medullaris cincto: cystocarpiis secus ramos sessilibus ......... Stenocladia. $" \quad$ in pinnula lateralibus oblique apiculatis... Spharococcus. 


\section{Delesserier.}

Redan i Species Algarum (pag. 676) uttalade jag den isigt, att slägtena $\mathrm{Hy}_{\text {- }}$ menena och Botryoglossum endast voro att anse såsom högre utvecklingsgrader men i olika riktningar - af Nitophyllum-former. De många Nitophyllum-arter från mera afligsna haf, som sedan dess blifvit beskrifna, synas mig beliäfta denna uppfattning: man måste numera antingen lita de båda slägtena ingå i Nitophyllum, eller öfverfora flera Nitophyllum-arter till Hymenena och Botryoglossum, och derjemte uppställa andra arter som skiljda sliggten. Men svårligen torde för de sålunda bildade nya slägtena characterer limna uppsökas af den beskaffenhet att de begränsa dessa slägten, eller i annat afseende kunna såsom slägt-characterer godkännas. Det stnes således vara lämpligare, att nu uppställa Hymenena och Botryogiossum såsom underafdelningar inom Nitophyllum.

Inom slägtet Delesseria synas deremot de många arter, som man äfven här beskrifvit, antyda att rissa förut såsom Delesseriex-former upptagna arter böra såsom sliiljda slägten uppstallas. Såval Grimnellia som Caloglossa synas vara egna typer, hvilka väl kunna såsom skiljda slägten upptagas.

Såräl slägtenas olika begränsning, som de många nyupptäckta arterne torde sålunda både inon Xitophyllum och Delesseria göra en ny uppställning af arterne behöflịg, och jag skall sảledes här nedan göra försök till en naturlig gruppering af de båda slägtenas arter.

Nitopleyllum. Cognita melius structura et fructificatione specierum, et comparatis speciebus recentius detectis, nescio sane quibus characteribus Hymenenam et Botryoglossum a Nitophyllo distinguere valerem. Nitophylla, olim fronde tenuiore distincta, cognitis $\mathrm{X}$. pristoideo, $\mathrm{N}$. cartilagineo, $\mathbf{X}$. Curdieano etc.; in quibus cellula multiplici strato transversaliter disponuntur, hodie hac nota ab aliis generibus discernere non licet. Venæ elevatæ, quiljus Iymenenam potissimum distinctam credidit Greville, in multis Auctorum Nitophyllis (X. Hillix etc.) xque proveniunt. Tee sori, lineas tenues flabellatas æmulantes, in omnibus iis proveniunt, quas Hymenenæ species judicarunt posteri; obveniunt nimirum in Hyn. fimbriata sori singuli in sporophyllis minutis; in Hym. latissima sori rotundati plurimi inter venas adsunt. Nec denique pericarpii structura notas certas offerre mihi visa est: pericarpium tenuius aut crassius a structura ipsius frondis derivandum videtur. Quod itaque jam in Specieb. Algarum monui, hæe genera non nisi gradu evolutionis differre, hodie adhuc magis certum puto. 
Cum his neutiquam dictum volui, characteribus non differre liversas sectiones; differunt sane et structura et fructu species extremæ; inter has extremas vero tot intermedias formas vidi, ut limites definire equidem frusta molitus sim. Laminam frondis ita in nonnullis monostromaticam vidi; in aliis cellulæ $6-7$ superpositæ inter utramque superficiem wumerantur. In speciebus monostromaticis, quarum sori sparsi, lamina sub soro quasi inordinate incrassata; in speciebus quarum sori marginales, stratum duplex adest et utriusque paginæ cellulæ fructiferæ sunt. Coccidia in multis non vidi; nondam itaque mihi liquet an in his differentix adessent, quibus certiores limites generum condere licerel. - Sit ut Arachnophylla quoque inter Nitophylla recipiantur; ignotis vero adlhue coccidiis, irritum putavi de his jam aliquid dicere.

Species Nitophylli hodie disponantur:

1. Aglaophyllum, Spherosporarum soris per totam frondem (aut superiorem partem frandis) fere aque sparsis, rotundatis, sensim centrifuge expansis.

+ Fronde tenuissima fere sessiti, venis omnibus (etiam in adultiore) destituta.

1. N. punctatum I. Ag. sp. p. 659 .

2. N. pulchellum Harv. Trans. Ir. Ac. Vol. 22 p. 549.

H† Fronde tenuissima brevius stipitata, nervo plus minus conspicuo stipitem percurrente, supra stipitem mox obsoleto.

* Fronde elongata integriuscula, aut quasi externa vi in lacinias ambitu subindefinitas vage fissa.

3. N. Crozieri Hook. et Harv. Crypt. antaret. tab. $17 \%$.

4. N. Grayanum (I. Ag. mscr.) stipite cuneato costato, costa supra stipitem in nervos plures mox evanescentes divisa, in frondem coccineam oblongo-lanceolatam aut integriusculam aut parcius laciniatam abeunte, soris minutis rotundatis per totam superficiem sparsis.

Ad Insulas Falkland (Hb. I. E. Gray).

Formam fere refert N. Smithii, quale figura media in Flora antarctica exhibeat, et nomine X. Smithii (manu, ni fallor, Harveyii) in Hb. Gray inseripta; at defectu venarum mihi diversa videtur. Minus quoque quam N. Smithii decomposita. N. Grozieri est tenuiore fronde et colore dilutiore predita species.

** Fronde elongata pinnatifide decomposita, nempe laciniis a margine excrescentibus, ambitu definitis, subpinnatim dispositis plus minus composita.

5. N. crispum Kütz.; I. Ag. sp. p. 662. 
*** Fronde latiore magis Alabelliformi et subpalmatim laciniata, laciniis nempe a margine excrescentibus sensim subpalmatim dispositis.

6. N. undulatum I. Ag. sp. p. 663.

7. N. denticulatum Harv. Nov. Zel. p. 241.

8. N. variolosum Harv. Nov. Zel. p. 241.

9. N. Gumnianum Harv. Phyc. austr. tab. 241.

tif Fronde supra stipitem proluctiorem subramosum tenuissima; nervo stipitem percurrente, segmenta principalia demum intrante, in his mox evanescente.

10. N. lividum Hook. et H. Crypt. tab. 179.

11. I. Bonnemaisoni Grev. Alg. Brit. et Auct. (mihi incertum anne duæ diversæe species sub hoe nomine venditentur).

12. N. crispatum Hook. et Harv. Crypt. ant. tab. 71.

tit广 Frondis lamina tenuissima venosa, nempe venis a costa provenientilus longius (per inferiorem partem) productis, sensim (et plerumque jam infra mediam laminam) evanescentibus.

13. N. venosmu Harv. Ner. austr. tab. 118.

14. N. Hilliar Grev. Crypt. Fl. tab. 351.

15. N. multinerve Hook: et Harv.; I. Ag. sp. p. 666.

16. N. Smithii Hook. et Harv. Crypt. ant. tab. 178.

17. N. latissimum (Hymenena latissima Harv.).

Ex Insula Vancouver.

18. N. litteratum ( $J . A g$. mser.) stipite brevi cuneato, in frondem venis dichotomo-anastomosantibus obseuriusculis inferne venosam, cuneato-reniformem subpalmato-pimnatifidam abeunte, lobis cuneato-linearibus margine minute undulatocrenulatis, basi contractis, soris inter venas seriatis, figuras irregulares inter se plus minus confluentes formantibus.

Ad littora meridionalia Anglix.

Nomine N. Hillix a D:na Griffiths mihi missa, aluunde diversa species. Foliola fere prolificationum modo a margine subpimnatim emissa, juvenilia linearia obtusissima, dein cuneata, sensim palmatisecta, omuia miṇute undulato-crenulata. Sori non punctiformes sparsi, ut in N. Hillix, sed lineares, oblongi aut varie configurati, inter venas seriati, lobos inferiores quasi litteris aut signis inscriptos reddunt. Substantia quam in N. Hilliæ crassior videtur.

†it十 Fronde fere avenia, at ipsa incrassata, sessiti aut inferne stipitem sensim costatum formante.

Lunds Univ. Årsskrift. Tom. VIII. 
* Soris per totam frondem fere aque sparsis.

19. N. cartilagineum Harv. in Trans. Ir. Acad. Vol. 22 p. 540.

20. N. erosum Harv. Alg. austr. exs. n:0 293.

** Soris in exteriore parte frondium evolutis $h$. e. segmenta exteriora terminalia aut lateralia occupantibus), in his numerosis.

21. N. Curdieanum Harv. Phyc. austr. tab. 151.

22. N. affine Harv. in Hook. Journ. 1844 q. $44 \%$.

23. N. Durvillai Bory; I. Ag. Sp. p. 666 .

24. N. multipartitum Hook. et Harv.'Alg. Tasm. p. \%.

Obs. Speciem hane judico ex specimine, quod olim dedit Harvey, lapsu calami, ut finxi, nomine $N$. multipunctatum inscriptum. Aliud specimen, inter Algas Australia distributum, vix differt a Nit. minori, cui sori infra apices segmentorum solitarii. Harvey ipse soros in apicibus numerosos descripsit et in Synopsi Phycol. Austr. N. multipartitum et N. pristoideum proxima enumeravit.

25. N. pristoidenm Harv. Phyc. austr. tab. 229.

26. N.\& Endiviafolium, Delesseria Endiviafolia Hook. et Harv. Alg. Tasm.p. 6.

Harvey speciem Delesseria consideravit, quin immo dubitavit an a D. frondosa differret. His comparatis tamen adpareat D. frondosam numquam apice subdivisam esse, sed semper evolutione marginali decompositam fore; in D. Endiviæfolia, contra, sunt segmenta terminalia dichotoma: sed hæc preterea quoque decomponitur evolutione laciniarum lateralium. Nihi D. Endiviæfolia mulıo magis cum quibusdam Nitophylli speciebus convenire adparuit: potissimum N. pristoideo, reque caulescente, adfinem suspicarer. Me tamen nec coccidia vidisse, nec soros bene evolutos, dixisse opportet.

II. Botryoglossum, Sphcerosporarum soris definito loco in fronde obvenientibus, nunc in lobo singulis, nunc secus margines seriatis, rotundatis aut pluribus confuentibus linearibus, singulis centrifuge expansis.

+ Soris infra apices laciniarum subsolitariis.

27. N. uncinatum I. Ag. sp. p. 654 .

28. N. ciliolatum Harv. Trans. Ir. Acad. Vol. 22 p. 549.

29. N. minus Sond. I. Ag. sp. p. 655.

30. N. acrospermum I. Ag. l. c. Agl. maculatum Kütz. tab. Phyc. Vol. 16 tab. 34 ? 31. N. monanthes $I . A g . l$. $c$.

Obs. Structura a præcedentibus sat differt. Venas microscopicas superficiales, quæ in illis, et quidem etiam in superioribus partibus vix desiderantur, in N. monanthe non vidi. Frondis autem lamina venis interioribus percursa adparet; transverse secta cellulas interiores superficialibus multo majores monstrat. Nec cellulæ 
superficiales sunt longitudinaliter seriatæ (longiores quam latæ), sed potius ommino inordinatx, rotundato-angulatx. N. monanthes Harv. in his cum nostra fere convenit; lamina autem tenuior et magis decomposita; tamen planta videtur magis juvenilis.

i† Soris marginalibus aut in lacinulis separatis marginis provenientibus.

32. N. Bartlingianum, Schizogl. Bartlingianum Kütz., mihi adhuc ignota.

33. N. marginale Harv. Alg. exs. ceyl. n:o 26.

34. N. Gmelini Grev. Alg. Brit.

33. N. laceratum Grev. Alg. Brit. (N. Smithii et N. laceratum Crouan).

36. N. fimbriatum $I$. Ag. $s p . p: 659$.

37. N. Ruprechtianum (I. Ag. mscr.). Hymenena fimbriata Post. et Rupr. Illustr. tab. 38 fig. a. Nit. laceratum var. palmatum Harv. ap. Beechey. Voy. p. 163.

38. N. platyearpum Turn. Hist. tab. 144. Botryoglossum platycarpum Auct. I. Ag. sp. p. 676. Neurogl. Binderianum Kütz.

III. Hymenena, Spharosporarum soris secus venas dispositis, in lineas elongatas confuentibus, latitudine vix expansis.

39. N. palmatum Harv. Nov. Zel. II. p. 240.

40. N. Harveyanum (I. Ag. mscr.) N. palmatum var pinnatifidum Harv. l. c.

Obs. Soros bene evolutos non vidi; an potius prope N. Durvillæi disponeretur?

41. N. fissum, Hymenena fissa Grev. Harv. Ner. tab. 44.

IV. Species affinitate incerta.

42. N. reptans Crouan $\mathrm{Fl}$. Finist. p. 153.

43. N. versicolor Harv. Phyc. Brit. tab. IX.

Obs. Species mihi dubias et inquirendas hoc loco omisi.

Delesseria. Quale genus in Speciebus Algarum a me adoptatum fuit, tale characteribus, at limitibus paulisper mutatis, hodie conservandum puto. Grinelliam nimirum et Caloglossam genera propria considerarunt, suadentibus characteribus quibusdam specialibus. Alind vero Genus, quod Chauviniæ nomine instituit Harvey, quomodo distinguatur vix video. In Del. coriifolia cellulæ majores, quæ simplici serie dispositæ intermedium stratum ut in cæteris efficiunt, cinguntur adparatu minorum fere ut in Callophyllide; qua quidem structura hæc species admodum igsignis certe consideratur. In $D$. Hookeri vero, quæ ad idem genus Chauvinix pertineret, hic adparatus vix conspicuus, nee in $D$. imbricata admodum notabilis. In exsiccala cellulæ intermediæ majores translucentes seriebus oblique adscendentibus dispositæ conspiciantur. Phylla sphærosporifera in D. coriifolia non admodum ab iis cæterarum specierum diversa: pagina folioli constat cellulis prægnantibus, duplici serie dispositis, 
quæ intermediis cellulis, his locis angustioribus, separantur, et corticalibus extrorsum teguntur. Cellulæ prægnantes e regione positx sphærosporas triangule divisas fovent. Coccidia in Ch. imbricata tantum observavi. Tectum pericarpii hemispherice supra paginam elevatur et pluribus seriebus cellularum contextum est; ipsa placenta, colore sæpe lutescens, cellula basali ramosa constituitur, inferne plexu subanastomosante adnata, quasi stipitata, depressa, sursum in ramos divisa; ramos fere fruticulum Griffithsix cujusdam referentes diceres: fila gemmidifera moniliformia, invicem libera, in articulis terminalihus gemmidia fovent: in fructibus itaque vix ullam notam video, qua Chauvinia ab aliis Delesseriis differret. Quæ in structura adest, vix ita pluribus speciebus constans, ut Harveyanum genus, ea ducente, adoptandum putarem.

Characteribus diversarum specierum melius cognitis, in dispositione specierum mutationes quasdam suscipere opportet. Najoris cujusdam momenti ea fructificationis differentia mihi adparuit, quam in situ sori monstrant species; pauex nimirum soros sparsos et quasi loco indefinitos, plurimæ soros utroque latere costæ quasi positione definitos gerunt. Qua quidem nota Schizoneuris separatis, pracipuum dispositionis fundamentum tum in ramificationis noriud, tum in evolutione costæ et venarum quæsivi. In iis, quarum ramificatio prolificationibus a costa provenientibus pendet, costa plerumque firmior, superficialibus cellulis costan investientibus, a parenchymate diversis quoque abludit. Sunt vero aliæ species, in quibus cellulæ superficiales costam obducentes vix hoe modo a cellulis parenchymatis differunt: costæ in his sunt quasi immersæ, nec frondes venis superficialibus initio notatæ. Quibus vero differentiis non nimium insistere opportet, quum differentix hoc respectu etiam in speciebus, quæ affinitate sunt proximæ, adsint. - Sectiones cyterum ita instituere molitus sum, ut oculo adsueto facilius dignoscerentur; ut facilius inveniantur, clavem dispositionis sequentem addere quoque placuit:

\section{A. Frondes divisione ipsius lamine ramosa, nempe c. subvage laciniato-partite:}

I. Schizoneura

B. divisione dichotoma, dichotomo-subpinnata:

II. Cryptoneura

III. Pteridium

$\gamma$. dentato-laciniate, dentibus laciniisve excrescentibus pinnatifido aut subpinnate, nunc insuper phyllis prolificantibus decomposita:

IV. Stenoglossum

V. Hemineura 
VI. Phycodrys

VII. Odontophora

B. Frondes lamina ipsa indivisa subintegra, aut raro parce divisa subdichotoma, prolificationibus a costa conspicua emeraentibus decompositce:

VIII. Hypoglossum

1X. Neuroglossum

X. Chauvinia

XI. Schizoglossum

XII.? Paraglossum

XIII. Hypophyllum.

I. Schizoneura. Frondes subvage laciniato-partita, ramis coste conspicuis, nun: sursum evanescentibus, ad lacinias principales excurrentibus. Coccidia sparsa in superficie parenchymatosa elevata, nune in nervo laterali evidentiori conspicua. Sori rotundati sparsi inter nervos numerosi.

* Costa alterne ramosa.

1. D. subcostata $I . A g . s p . p .681$.

2. D. dichotoma Hook. et Harv. Crypt. ant. tab. 71 fig. 2.

3. D. Davisii Hook. et Harv. l. e. tab. 175. ** Venis a costa oppositis.

4. D. Hookeri Hook. et H. Fl. Nov. Zel. tab. 114-115.

כ.. D. Quercifolia Bory Coqu. tab. 18 fig. 1. Harv. Ner. austr. tab. 46.

II. Cryptoneura. Frondes angustissimce ancipites, alis fere destitute, subpinnatim ramosissima. Coccidia in medio segmento incrassata, ita coste licet obscurce imposita. Spharospore in apicibus segmentorum aut in sporophyllis propriis evoluta, soro fere in unum confluente (costam pariter ac latera occupante.

6. D. rostrata I. Ag. sp. p. 685 .

7. D. Baerii Post. et Rupr.; I. Ag. ibm.

8. D. corymbosa I. Ag. ibm p. 684 .

9. D. angustissima Griff., I. Ag. ibm. p. 686.

10. D. Inergensii I. Ag. sp. p. 68\%. Del. complanata Rupr.

III. Pteridium. Frondes lineares alterne dichotomo-pinnata, ala conspicua costam marginante. Coccidia in medio segmento aut in phyllo prolificante axillari evoluta (ita costa imposita); spharosporce in apicibus segmentorum aut in sporophyllis propriis evolute, soris secus costam 
expansis, fere in unum confuentibus (costam pariter ad latera occupantibus).

11. D. alata $I . A g . s p \cdot p .603$.

12. D. spimulosa I. Ag. mser; D. Beeringiana var. spinulosa Rupr. Alg. Ochot. p. 243. An D. denticulata Mont. Syll. p. 408 P

13. D. pleurospora Havv. Nov. Zel. 1. 238. D. propinqua I. Ag. in pl. Hohenackeri; D. laciniata Kütz. tab. Phyc. Vol. 16 tab. 19?

IV. Stenoglossum. Frondes angusta fere lineares, obsoletius immerse costata, laciniis excrescentibus subpinnatim decomposita, pinnis ala decurrente confluentibus. Coccidia - - . Sori spharosporarum utroque latere coste oppositi, singuli aut in unum ambo confuentes, (in segmentis ipsius frondis aut in phyllis minoribus evoluti).

14. D. Schousboei $I$. Ag. sp. p. 688.

13. D. Woodii (I. Ag. mscr.) fronde costata lineari pinnatifide ramosa, margine integerrima, laciniis linearibus utrinque longe attenuatis obtusiusculis, soris utroque latere costa singulis oppositis margini adproximatis media segmenta majora occupantibus.

Hab. ad insulam Vancouver D:r C. B. Wood. (Hb. Gray!).

Ad sectionem Stenoglossi pertinet species facilius distincta. Frons est 3-4. pollicaris, lineam vix latitudine superans, admodum decomposita, lacinis a margine frondis ubicumque linearis rage egredicntilus, majoribus basi aliquantulum attenuatis, apicibus obtusius acuninatis. Laciniæ juveniles magis distantes, inferiores longiores, superiores lacinias (nee dentes aut cilia) amulantes. Sori utrinque fere marginales conspicui, in media parte fere laciniarum majorum evoluti, invicem bene separati, lineam dongatam formantes. Costa media latiuscula, in superiore parte fere obsoleta.

Duplo angustior quam D. Schousboei et D. bipionatifida, est magis quam hæ: species decomposita. Lacinia integerrimx dicendxe et lineares, nec ciliato-serratæ et lanceolata ut in D. bipinnatifida. D. Schousboei est forma latior, minus decomposita; quasi inter alias intricata fuisset, est modo Rh. bifidx marginibus adhærens, cellulisque majoribus areolata.

Ut in proximis specicbus segmenta nunc opposita, nune paria plura alproximata, nune singula proveniunt. Sori elongati lineares.

16. D. bipimnatifida Mont. Voy. d'Orb. tab. VI fig. 1.

V. Hemineura. Frondes sinuato-pinnatifida, laciniis excrescentibus decomposita, evanescenti-costate, costis costulisque immersis sensim magis conspicuis ad lacinias majores excurrentibus, nunc basi apiceque fere 
obsoletis. Coccidia coste sensim formate imposita. Sori spharosporarum maculas plures intra marginem seriatas subdiscretas formantes.

17. D. frondosa Harv. Phyc. austr. tab. 179.

18.? D. cruenta Harv. Fl. Nov Zel. p. 240 (mihi ignota).

VI. Phycodrys. Frondes sinuato-pinnatifide, laciniis excrescentilus, nunc quoque phyllis a costa provenientibus decompositce, sensim immerse costata, costulisque plus minus conspicuis costam continuantibus sapius instructe. Coccidia sparsa, costulis aut parenchymate imposita. Sori spharosporarum secus costam expansi oppositi sape in unum confluentes, costam pariter ac latera occupantes, in apicibus segmentorum aut in phyllis minoribus evoluti.

* Venis obsoletissimis vage excurrentibus.

19.? D. intermedia ( $I$. Ag. mscr.) frondis obsoletissime costatæ, vage vix venosæ foliis stipitatis lineari-cuneatis dentatis, dentilusque excrescentibus sensim pinnatifidis, laciniis conformibus aveniis demum foliola marginalia plurima stipitata constituentibus, stipitibus linearibus subcostatis, soris _ _ —. Nitophylli sp. Harv. mser.

Hb. ad insulam Vancouver.

Habitus D. sinuosæ lingulatæ, sed juvenilis tere omnino avenia, Nitophyllum referens, adultior vage venosa. Fructibus ignotis proxima affinitas dubia manet. ** Venis magis conspicuis subregulariter oppositis.

20. D. fimbriata I. Ag. sp. p. 690.

21. D. sinuosa Good. et W.

22. D. crassifolia Rupr. Alg. Ochot. p. 232.

25. D. phyllophora (I. Ag. mscr.) frondis costatx opposite venosæ foliis obovatooblongis sinuatis et parce divisis, laciniis costatis sensim separatis phyllisque a costa secus laminam sensim detersam utrinque provenientibus, frondem nunc foliosissimam constituentibus, coccidiis supra venas prominulis, soris — - Deless. erassinervia (partim) Hook. et Harv. (non Montagne).

Ad Insulas Falkland.

Nomine D. crassinerviæ plures species distinctissimas confundi suspicor. Primaria D. crassinervia, a Montagneo depicta, quam nec ipse vidi, nec Harveyum comparasse suspicor, ramificatione D. Hypoglossi, foliis lanceolatis indivisis enervibus (sec iconem Montagnei) insignis, D. dendroide aut D. oppositifoliæ potissimum propinqua videtur. Alii postea sub nomine D. crassinerviæ intellexerunt formas diversarum specierum, quas costa valida congruentes, sxepius phyllis novis e senili costa proli- 
ficantibus instructas, viderunt. Kützing ita specimen a Hookero ditum e Kerguelen land depinxit (Tab. Phycol. Vol. 16 tah. 12), cui laciniam dichotomam venisque alternis instructan! adjecit. Ipse ex insulis Falkland specimen coram habeo, manu Harveyi ni fallor, nomine D. crassinervix inscriptum, quod mihi nullomodo speciem e sectione Hypoglossi prodit. Ut in planta vetusta costa est valida et adparenter derasa, phyllisque plurimis sine ordine a costa pullulantibus; foliola obovara-oblonga opposite venosa (licet venx admodum inconspicux), longe stipitata, stipite foliola minora a margine exserente. Hoc congruere puto cun fragmentis aliis, ex iisdem insulis provenientibus, qux speciem D. sinuosx aut D. quercifolix subsimilem referunt, quam nonine D. phyllophora designavi.

III. Odontophora. Frondes e margine folifere, nempe phyllis indivisis (aut externa vi tantum laceratis) margine dentatis dentibusque marginalibuz excrescentibus sensim decompositis constituta, costis evidentibus costulisque oppositis ad dentes excurrentibus percursa. Cocidia sparsa. Sori in phyllis marginalibus evoluti, in majori plures oblique transversales et subdiscreti, in minori singuli.

24. D. Lyallii Hook. et Harv. Crypt. ant. tab. 176.

25. D. similans (I. Ag. mscr.) fronde a margine foliefera phyllis indivisis ellipticooblongis margiue ciliato-appendiculatis, appendiculisque marginalibus excrescentibus sensim pinnatis constituta, costa costulisque angustis oppositis subexterue distinctis, cellulis costularim supcrficialibus elongatis a cellulis parenchymatis diversis, phyllis soriferis minutis margine ciliato-spinulosis. D. Lyalliz Harv. Alg. austr. exs. n:o $2 \% 1$ (nec. Fl. antaret.).

Ad Yovam Hollandiam.

D. Lyallii certe simillima, at me judice distincta species. Foliola frondis sunt longiora, venis pluribus et strictionibus perenrsi. Margines obsoletius serrati, demum dense minute appendiculati (in D. Lyalii duplicato-serrati). Venæ jam in juvenili conspicna; sul, microsepio adpraret cellulas superficiales costularum esse elongatas et a parenchymate interjacente facitius distinguendas. In D. Lyalli vera hæe differentia cellularuin vix conspiciatur.

26? D. ovifolia Suhr. Kütz. tab. Phyc. Vol. 16 tab. 19 (mihi ignota).

VIIl. Hypoglossum. Frondes prolificationibus a costa emergentibus ramosa, caterum indivisa, venis transversalibus microscopicis destituta, tenuissima, cellulis jarenchymatis in series subtransversales, a costa arcuatim versus marginem excurrentes, fere ordinatis. Cocidia costa insi- 
dentia. Sori spharosporarum in foliolis vix mutatis evoluti, utroque latere coste singuli.

* Costa ecorticata, nempe seriebus cellularum longitudinalibus paucis constituta, quasi articulata.

27. D. teunifolia Harv. Ner. Bor. Americ. tab. XXII. B.

28. D. involvens Harv. 7. c. tab: XXII. A.

29. D. Hypoglossoides Har?. Phyc. austr. tab. 8\%.

Specimen nomine D. spathulatx a Harvey distributum, ex Fremantle ortum, mihi D. Hypoglossoidi admodum propinguum adparuit. Specimina alia, mihi diversa, e King Georges Sound gerunt frondis tenuissima margines amplos eximie undulatos. Nec in his plantam Sonderi primitus descriptam rocognoscere credidi, utpote suam D. spathulatam striis pellucidis notatam descripsit Sonder. Quo quidem charactere speciem Sonderi D. ruscifolix affiniorem esse, suspicari licet.

* Costa max corticata, nempe cellulis elongatis numerosis non e regione positis (et quasi articulos formantibus), sed vage desinentibus obtecta.

r. Prolificationibus subunifariam a costa media prorumpentibus, frondem vage ramosam formantibus.

30. D. Hypoglossum Woodw.

B. Prolificationibus a coste latere alterutero juxta laminam prorumpentibus, subsingulis, frondem subvage ramosam formantibus.

31. D. Harreyana (I. Ag. mscr.) fronde corticato-costata, prolificationibus a costæ latere alterutero juxta laminam prorumpentibus subsingulis vage ramosa, foliolis lanceolato-ellipticis apice obtusiusculis evenosis, margine minute et acute serratis, soris - - coccidins costæ impositis subsingulis. D. serrata Harv. Alg. austr. 'exs. n:0 2\%, nec Post. et Rupr.; D. serrulata Harv. Phyc. austr. tab. 59. Nomine D. serrulata Harvey duas species distinctas comprehendit.

Ad Tovam Hollandian.

$\gamma$. Prolificationibus infra apicem revolutum geminatim prorumpentibus, demum frondem adparenter dichotomam formantibus. An Caloglossa adfinior?

32: D. revoluáa Harv. Phyc. austr. tab. 170.

d. Prolificationibus ab utroque latere costa juxta laminam prorumpentibus geminatis, demum frondem sub opposite ramosam formantibus.

33? D. crassinervia Mont. Voy. Pol. Sud. tab. 8 fig. 1.

Lunds Univ. Arsskrift. Tom. VIII. 
34. D. dendroides Harv Phyc. austr. tab. $13 \%$.

IX. Neuroglossum. Frondes prolificationibus a rosta emergentibus ramosa, caterum indivisa, venis microscopicis a costa transversaliter egredientibus instructa, interjacentibus cellulis parenchymatis quasi inordinatis (nec lineas flabellato-radiatas a costa egredientes formantibus).

* Soris foliola frondis vix mutata occupantibus.

a. Prolificationibus ab utroque latere coste juxta laminam prorumpentibus geminatis, demum frondem sub-opposite ramosam formantibus.

35. D. oppositifolia Harv. Fl. Nov. Zel. p. 239.

36. D. decipiens (I. Ag. mscr.) fronde mox corticato-costata, prolificationibus ab utroque latere costa juxta laminam prorumpentibus geminatis demum frondem opposite ramosam formantibus, foliolis valide costatis lineari lanceolatis margine integerrimis, venis microscopicis a costa excurrentibus demum sat conspicuis ramosis, interjacentibus cellulis oblongo-rotundatis, soris utroque latere costæ distinctis aut subeonfluentibus. D. Hypoglossum var. arborescens Harv. mser.

Ad Insulam Vancouver.

Venæ opposita in tronde adultiore tere mudo oculo conspicux. Structura magis ad D. ruscifoliam, quam ad D. Hypoglossum tendit. Ramificatione ad antecedentes accedit.

ß. Prolificationibus a coste latere alterutero juxta laminam prorumfentibus subsingulis, frondem subvage ramosam formantibus.

37. D. violacea (I. Ay. mscr.) tronde corticato-costata, prolificationibus a costæ latere alterutero juxta laminam prorumpentibus subsingulis vage et fere alterne ramosa, foliolis lineari-lanceolatis utrinque attenuatis margine serratis, venis microscopicis a costa excurrentibus, interjacentibus cellulis parenchymatis angulatis, soris utroque latere costa evolutis in unum contluentibus. Del. serrulata Harv. in Perrys. exp. to Japan Bot. append. p. 331 (nec Phyc. austr.).

Ad Japoniam.

Præsentia venularum a D. serrulata Australiæ facilius dignoscatur.

$\gamma$. Prolificationibus a media costa subunifariam prorumpentibus subsingutis, frondem vage ramosam demum formantibus.

38. D. ruscifolia Turn.

39?. D. spathulata Sond.; nee Harvey (mihi ignota). ** Soris phylla minuta sub-propria occupantibus.

40. D. Tasmanica F. Muell; Hook. Fl. Tasm. tab. 190 B.

41.? D. Nereifolia Harv. Nov. Zel. p. 238 (mihi ignota). 
X. Chauvinia. Frondes prolificationibus a costa emergentibus ramosa, caterum indivisa, venis transversalibus destituta, at ipsa crassiuscula, cellulis infra-corticalibus translucentibus areolas hexagonas monstrantibus.

42. D. imbricata Aresch. Chauv. imbricata Harv. Phyc. austr. tab. 240.

43. D. coriifolia Harv.; Ch. coriifotia Harv. Phyc. austr. tab. 150.

XI. Schizoglossum. Frondes dichotome et prolificationitus a costa emergentibus ramosa. Coccidia - _ - Sori utroque latere costa singuli aut in unum confluentes, folioli partem aut phylla subpropria occupantes.

44. D. crispatula Harv Phyc. austr. tab. 268.

45. D. denticulata Harv. Phyc. austr. tab. 244.

XII.? Paraglossum. Frondes foliis simplicibus constitute aut prolificationibus a costa nervisque lateralibus secus laminam utrinque provenientibus, demum lamina detersa in phylla nova (nunc plurima) evolutis, ramosa. Coccidia - - (nervis lateralibus insidentia?). Sori in phyllis minoribus adparenter secus costam evoluti, in majoribus secus nervos laterales costam versus subtransversi, oblongi. (Costa venaque corticate cellulis brevibus, ab aliis parenchymatis vix diversis).

46. D. lancifolia (I. Ag. mscr.) fronde simpliciuscula elongato-lanceolata utrinque longe acuminata subundulata valide costata nervisque lateralibus oppositis demum conspicuis instructa, prolificationilus a costa venisque emergentibus (raris) demum ramosa, soris in phyllis minoribus arlparenter secus costam longitudinalibus, in majoribus secus nervos laterates in soros plures oblongos costum versus transversales separatis. D. sanguinea var. lancifolia Hook. et Hart. Fl. Ant. p. 470 ?

Ad Cap Horn in Hb. Gray.

Donec coccidia inveniantur, affinitas mihi dubia manet. In unico specimine fertili, quod vidi, sori et in phyllis minoribus a costa prolificantibus et in majoribus obvenerunt; in majoribus inferne distincti, in apice folii confluentes. Habitus et color D. sanguineæ; me judice, neutiquam cum hac identica species. Cellulæ corticales costæ breves, nec elongatæ ut in Hypoglossis.

47. D. epiglossum (I. Ag. mscr.) fronde (demum foliosissima) ovali-lanceolata undulata valide costata, nervisque lateralibus oppositis minus conspicuis instructa, prolificationibus utroque latere costæ secus laminam provenientibus phrimis, de- 
mum lamina detersa in foliola conformia plurima excrescentibus, fructibus - Del. crassinervia Hook. et Harv. partim?

Ad Insulas Falkland in Hb. I. E. Gray.

Folia saltem 4-ä pollicaria, aliquando ultra pollicem lata, quo latiora eo magis margine undulata, ipsa simplicissima; phyllis plurimis a costa prolificantibus frons ramosa adpareat. Cellulæ corticales costæ et venarum breves et angulatæ, vix ab illis parenchymatis diversæ.

XIII. Hypophyllum. Frondes prolificationibus a costa media subfasciculatim emergentibus, demum lamina detersa in phylla nova (sapius plurima) evolutis, ramose. Fructus - -.

48. D. Middendorfiii Rupr. Alg. Ochot. tab. 12 . 



SMITHSONIAN INSTITUTION LIBRAAIES

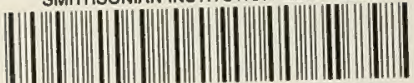

$\begin{array}{llll}3 & 9088 & 00731 & 3257\end{array}$

18 